\title{
The Effect of Smoking on Oxygen Free Radicals in Smoking and Non- Smoking Athletes Amr Farouk Ismail Sallam
}

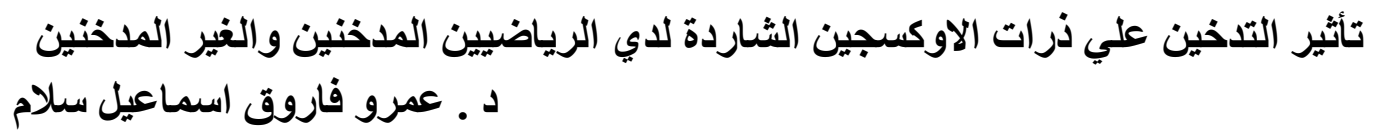

There are some bad traditions that might be acquired from interrelation with friends, such as smoking, which is one of the most common problems in the modern age. There are about a billion and 100 million regular smokers all over the world of which 300 million are in the developing countries and 800 million are in the developed societies.

In spite of the importance of oxygen in producing energy and its various benefits for the body, yet it also has destructive side effects that cause the formation of oxygen free radicals. They are formed in all the living tissues that are exposed to a momental deficiency in the blood stream coming into it and going out once again to the cellulous membranes, and the whole matter ends up with destroying those tissues a full destruction.

The effect of free radicals that are formed by oxidation lies in its important role in tearing muscles and causing inflammations after the hard exercises for athletes, so the rate of the free oxygen radicals increases with an apparent percentage which leads to consuming oxygen that by its turn, leads to an increase in the oxidation of fats that are considered one of the important sources of producing the free radicals in the body.

As Cooper has clarified, despite the dangers of the oxygen free radicals, the human body still needs it but with little percentage, he has also elucidated that free radicals are formed of 2 oxygen molecules in an unstable state due to the extraction of an electron. As a result, when this $\mathrm{O}_{2}$ molecule starts attacking the cells, it causes damage in the cell wall or the cell main components. It also attacks the nucleus and causes in the DNA or RNA genetic strings.

مدرس بقسم علوم الصحة الرياضية - جامعة أسيوط ( فرع الوادي الجديد ) 
That is why it has been important to be acquainted with the effect of smoking on the oxygen free radicals in both smokers and non-smoker.

\section{Research objectives:}

The research aims at knowing the effect of smoking on:

1- The oxygen free radicals and their effect on DNA.

2-The oxygen free radicals on the oxidation of fats

and proteins in both smoking and non- smoking athletes.

3-SOD enzyme as one of the antioxidants in both smoking and non-smoking athletes.

\section{Research Hypothesis:}

1-The damage that happens in the DNA in non-smoking athletes is less than that in smoking athletes.

2-The percentage of oxidation of fats and proteins in athletes is less in non-smokers than smokers.

3- The percentage of the SOD enzyme as one of the natural antioxidants in smokers is higher than in non- smoker athletes.

\section{Research procedures:}

Methods: The researcher used the descriptive method that suits these studies. The sample comprised 20 athletes of the first degree in sport activities as (handball, basketball) they are apportioned (divided) into two groups as follows:-

$1^{\text {st }}$ group 10 smoking players.

$2^{\text {st }}$ group 10 non-smoking players.

\section{Instruments and devices use in the research:}

1- Medical scale for measuring weight.

2- Rest meter for measuring length.

3- Spector-photometer for analyzing blood lactics.

4- Centrifuge device for separating blood components (3 hours).

5- Ice box containing crushed ice for putting the plasma tubes.

6- Chemical substances to preserve blood clotting such as the heparin. 


\section{Steps:}

\section{The level of oxygen free radicals has been measured as follows:}

1. A blood sample has been taken $(10 \mathrm{~cm}$.).

2. $2 \mathrm{~cm}$. has been separated to be used over the blood serum.

3. Using sum detectors to indicate the level of oxidation of fats and proteins, the damages that happen in the DNA and the SOD enzyme.

\section{Conclusions:}

According to the results of the research and through the sample and the methods used in the research, and through the statistic treatment and by analyzing the results, it was possible to reach the following conclusions:

1-Smoking increases the amount of the oxygen free radicals in the body tissues.

2-Smoking affects DNA manufacturing as it leads to producing abnormal DNA.

3-Smoking makes a change in the kernel shape and its structure which effects the DNA and its repairing.

4-Smoking is considered a direct cause for cancers due to the damage it causes to the DNA.

5-Smoking increases MDA in the blood plasma which causes lipids Peroxidation.

6-Smoking leads to increasing peroxidation of blood plasma proteins.

7- SOD enzyme as an antioxidant is secreted with large amounts to resist the free radicals caused by smoking.

\section{Recommendations:}

In concern of the research objectives, its hypothesis, the conclusion, and in the frame of the research nature and according to the conclusions and the importance of the athletic program, the researcher would recommend the following:

1-The trainers should aware the players of the harmful effects of smoking and recommend them to maintain themselves from it .

2-Using the laboratory measures in evaluating the athletes such as measuring the oxygen free radicals and the antioxidants.

3-The importance of making scientific researches in this field especially the effect of athletics on the level of the O.F.R. 
4-Making a comparative study on the effect of the oxygen free radicals in both smokers and non-smokers athletes.

\section{مقدمة ومشكلة البحث :}

هنالك بعض العادات السيئة التي قد تكون مكتسبة من مخالطة الاقران مثل التدخين ، فلقد أتثتت الدر اسات زيادة عدد المدخنين في مصر بمعدل 8 \% سنويا تقريبا ، كما اثتتت أيضا أن التدخين يقتل سنويا ثلاثة ملايين فرد في كاني العالم ، أي بمعدل وفاة شخص كل عشرة ثواني طبقا لتقرير منظمة الصحة العالمية عام 1995 ( 5: 103 ) .

وظهرت في الآونة الاخيرة نظريات تؤكد أن العو امل البيئية المحيطة بالاعب كالهو اء ومدي نقاءه تلعبا دور ا في حدوث تلف لجزيئات الأوكسجين التي تؤدي الي تلف الخلايا و الأنسجة ، حيث لوحظ أن كثير من اللاعبين قدالث

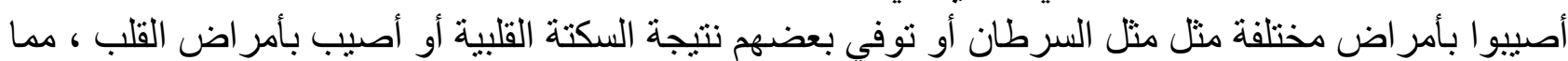
دفع العديد من الباحثين الي دراسة هذه الظاهرة وتوصلو الي سبب هذه المشكلة هو مايعرف بالثوارد الثرد الحرة

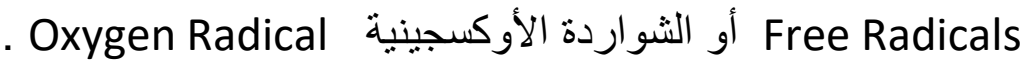

وتتكون ذرات الاوكسجين الشاردة النشطة في جميع الأنسجة الحية التي تتعرض للنتقص اللحظي من تدفق الدم الوارد اليها ثم عودة مرة اخري و التي يرجع اليها فيما يصيب الخلايا تحت هذه الظروف من آثار مدمرة تنتج جزئيا من تفاعل هذه الذر ات مع الدهون الفسفورية للأغشية الخلوية وتكوين البيروسيدات فيها وينتهي الأمربتدمير

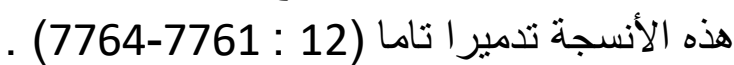

ان هناك تأثثير اللجزيئات الحرة الناتجة من الأكسدة فلها دور كبير في تمزيق العضلات و الالتهابات التي تحدث

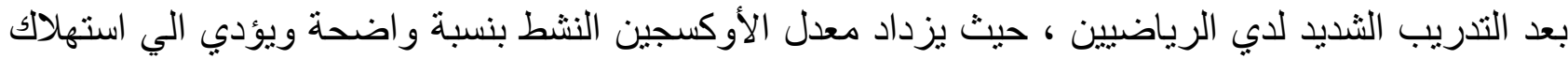

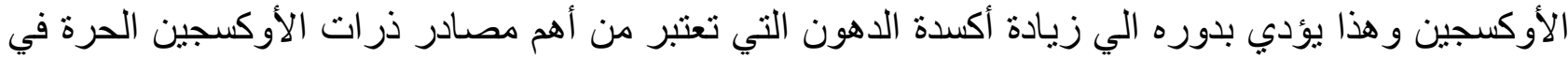
الجسم (12 : (1761 )

كما أكد كوبر 1994 Cooper أنة بالرغم من خطورة الثوارد الحرة الأوكسينية الا أن الجسم يحتاج اليها ولكن بنسبة قليلة ، وذلك لأنها تعمل علي تنشيط جهاز المناعة الذي يساعد علي الوقاية من بعض الأمراض ، كما أنها تساعد في تتظيم الاتقباض العضلي ، وكذلك تساعد في عملية سريان الدم داخل الأوعية الدموية ، كما

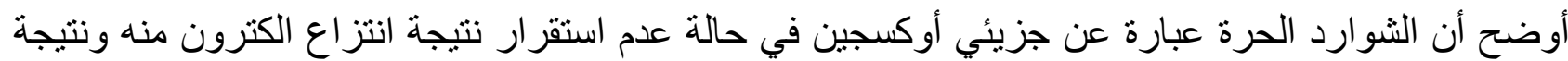

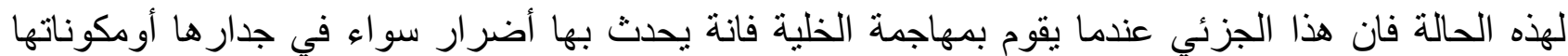

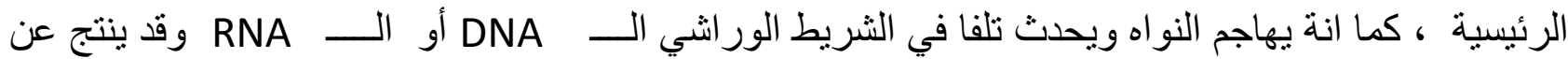
هذا التغير الاصسابة بالعديد من الأمر اض منها السرطان والثيخوخة المبكرة وأمر اض القلب (20). 
عندما يتعرض الاعب لجو يحتوي علي ثمانين جزء أ في المليون من غاز أول أكسيد الكربون لمدة ثماني ساعات

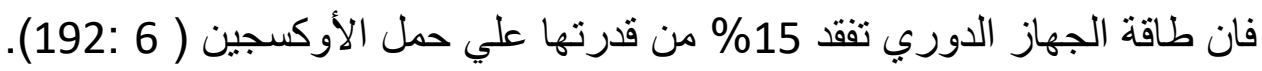

هناك تأثير للثوارد الحرة الناتجة من الأكسدة في تمزق العضلات والالتهابات التي تحدث بعد التدريب الثديد

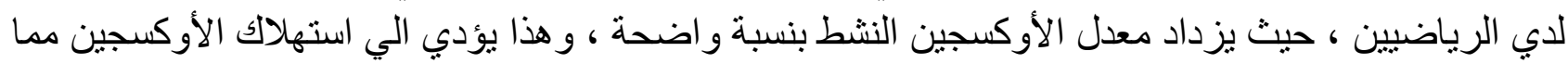

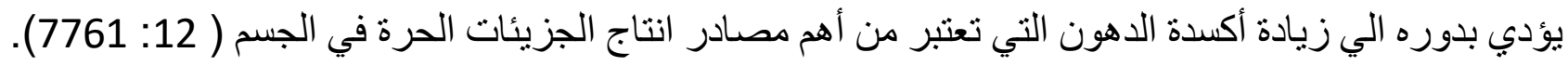

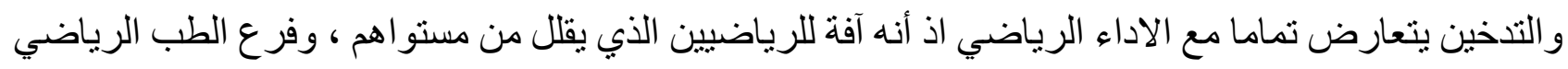

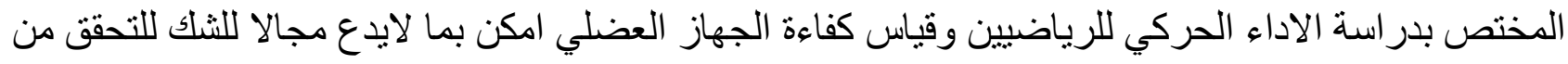

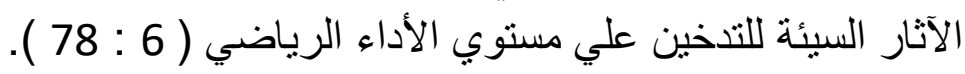

لذا يري الباحث عن أن مشكلة هذه الدراسة تكمن في وجود رياضيين يدخنون والذين قد يتعرضون الي زيادة

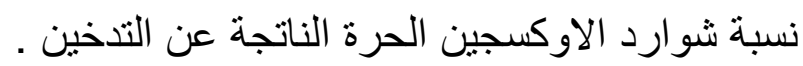

و هذه الدراسة هي محاولة علمية للتعرف علي تأثير التنخين علي زيادة ذرات الأوكسجين التي يمكن الاستدلال

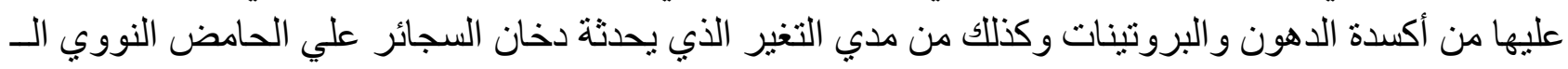

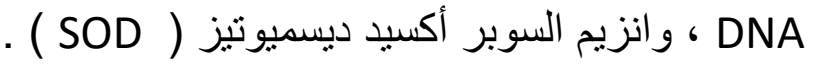

$$
\text { أهداف البحث : }
$$

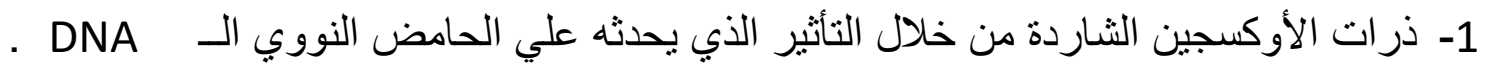

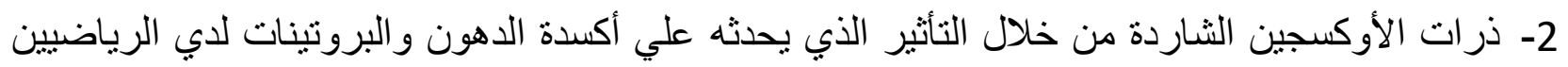

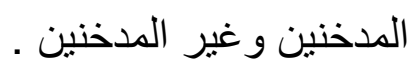

3- إنزيم السوبر أكسيد ديسميوتيز ( SOD ) كأحد مضادات الأكسدة لدي الرياضيين المدخنين و غير المدخنين.

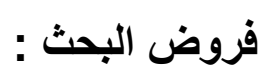

1- التكسير الذي يحدث في خلايا الثريط الوراثي الـ ـ DNA للإياضيين الغير مدخنين أقل من نظيره

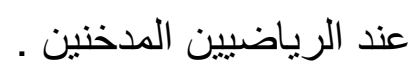

2- نسبة أكسدة الدهون والبروتينات لابي للرياضيين الغير مدخنين أقل منها عند الرياضيين الدذخنين .

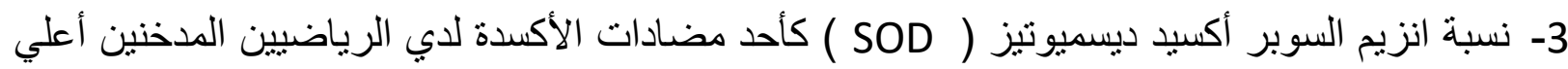

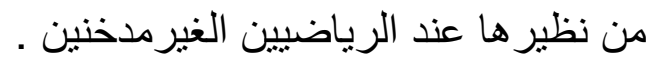


" هو ادخال بعض المو اد السامة المكونه من القطران و النيكوتين وأول أكسيد الكربون ومادة البولينيوم وبعض

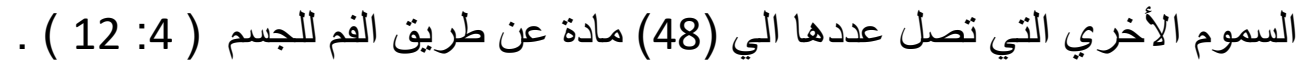

المدخن : SMOHER هو من يدخن سيجارتين يوميا علي الأقل بدون اتقطاع لمدة عامين (7 : 79) .

ذرات الأوكسجين الثاردة FREE RADICALS هي ذرات شاردة من الأوكسجين تتلف وتدمر الخلايا عن طريق تكسير الحاجز الو اقي الذي يحيط بالنو اهوذوذللك

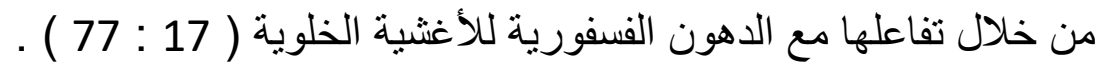

مضادات الأكسدة ANTIOXIDANT هي عبارة عن نظام دفاعي ضد ضغادة الأن الأكسدة الذي تسبيه ذرات الأكسجين الثاردة لحماية الخلايا من أضرار

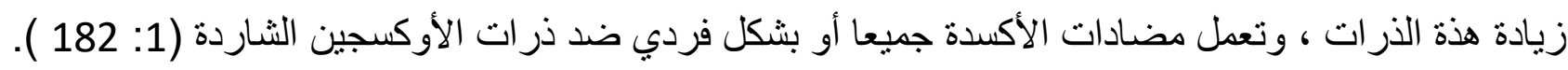

ضغط الأكسدة OXIDATIVE STRESS هو عملية التوازن بين انتاج الثوارد الحرة وكمية مضادات الأكسدة بالجسم ( 16 ) .

-: PROTEIN CARBONIYL أكسدة البروتينات هي ناتج من الثطور الحر الذي يهاجم جزيئات البروتين الموجود في الجسم ( تعريف اجرائي ) .

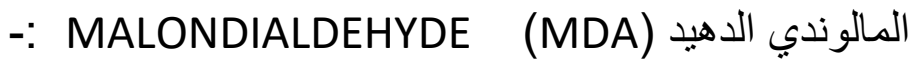
هو عبارة عن مركب عضوي ينتج عن عملية أكسدة الدهون ويستخدم كمؤثر لمستوي الثوارد الأوكسجينية

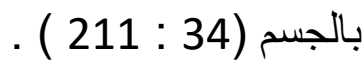

-: SUPEROXIDE DISMUTASE ( SOD ) انزيم السوبر أكسيد ديسميوتيز انزيم طبيعي موجود في الجسم يزيل شطائر الأوكسجين الحر ، و ويعتبر خط الدفاع الأول للجسم ضد ذرات

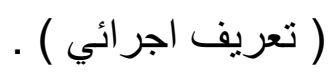

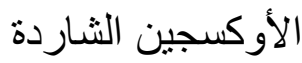

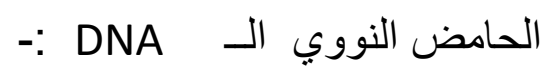
هو عبارة عن جزئ طويل يحتوي علي الثفرة الوراثية الفريدة لكل شخص ، و التي تحمل تعليمات بناء

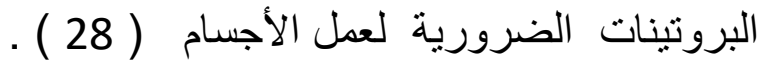


في در اسة قام بها أحمد سامح (2011) ( 3 ) بعنوان " الثوارد الحرة تدمر خلايا أنسجة الجسم " حيث أثبتت الدر اسة ان هنالك تفسير جديد للاصابة بالأمر اض وتلف صحة الانسان بسبب تعرض خلان خلايا الجسم للمئات من

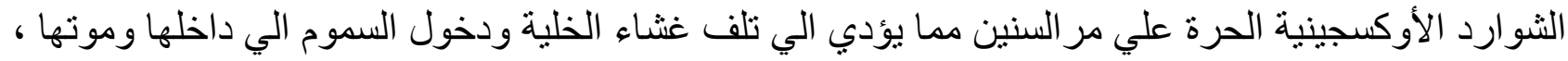

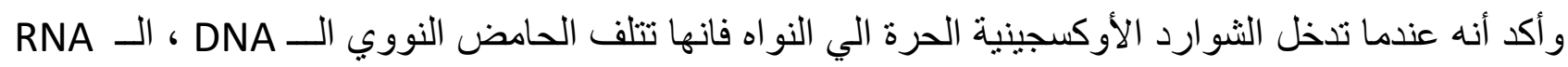

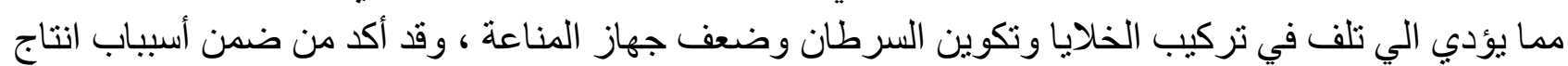

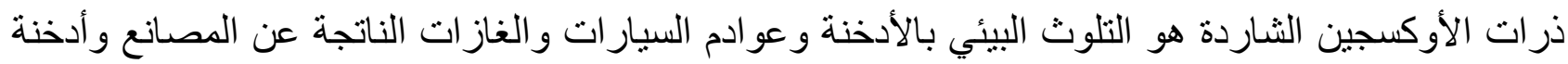
التدخين بأنو اعه . كما ذكرت در اسة أحمد صلاح عبد الحميد ( 1999) ( 2 ) بعنوان " تأثنير الجهد البدني الأقصي علي مستوي

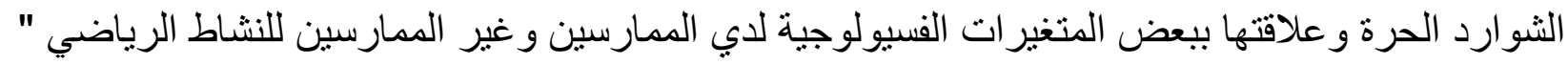

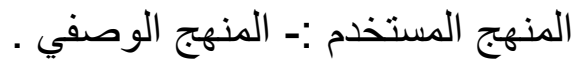
عينة البحث :- تم اختيار مجموعتين متكافئتين في السن والطول والوزن ومنساوبين كل منهما ( 15 ) فردا ،

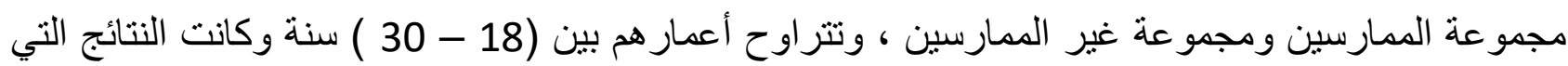

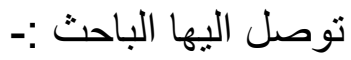
أـ أن زيادة الحد الأقصي لأستهلاك الأوكسجين لا بعني بالضرورة زيادة الثوارد الحرة حيث لم توجد أي التي

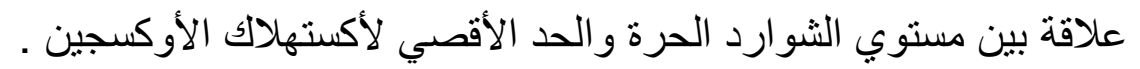

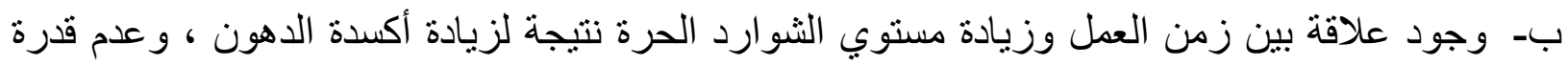

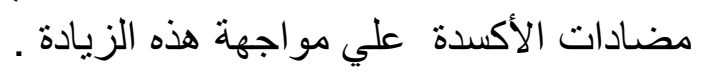

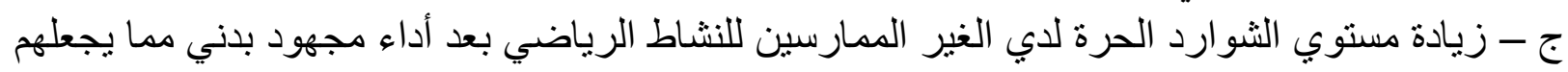

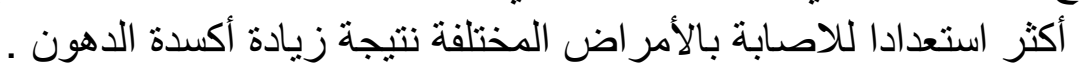

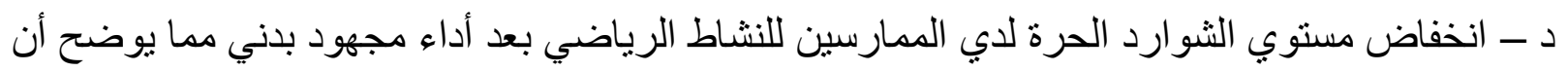

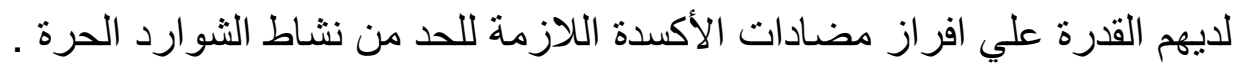

في حين ذكرت در اسة خالد جلال عبد المنعم - ماجستير عام ( 1999) ( 6 ) بعنوان " تأثثر الحمل البذني الهو ائي و اللاهو ائي علي انزيم الجلوناثيون كأحد مضادات الأكسدة و علاقته بمستوي حمض اللاكتيك في الام ".

المنهج المستخدم :- المنهج النجريبي ، عينة البحث :- اشتملت عينة البحث علي مجمو عتين :-

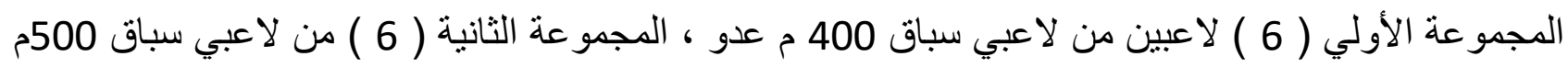

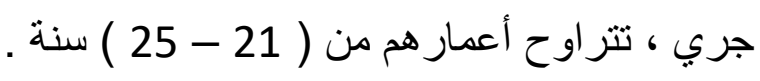
نتائج الدر اسة :- أـ توجد علاقة بين نوع اعلن النشاط الرياضي ومستوي ذر ات الأوكسجين الشاردة وتركيز الجلوناثيون المخنزل ـ بـ توجد علاقة بين مستوي حمض اللاكتيك في الدم ومستوي الأكسدة في العمل الهوائي و اللاهو ائي حيث وجدت علاقة طردية بين مستوي حمض اللاكتيك ومستوي الجلوتاثيون المؤكسد .

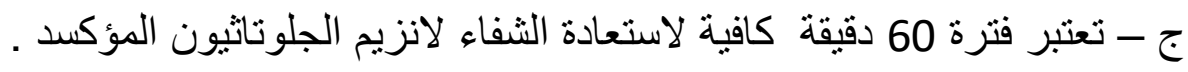


أما بالنسبة للار اسات الاجنبية فقام 1994 KANTER عام ( 19 ) بدر اسة بعنوان " ذرات الأوكسجين

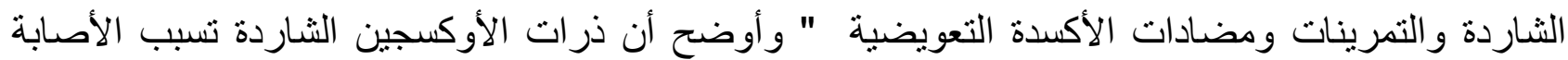
ببعض الأمر اض مثل السرطان والسكر والمياه الزرقاء وقد أثتتت بعض الدرات واستات وجود وداد علاقة بين مضادات

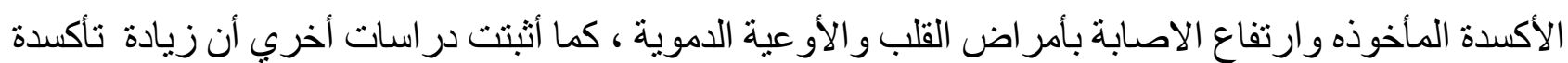

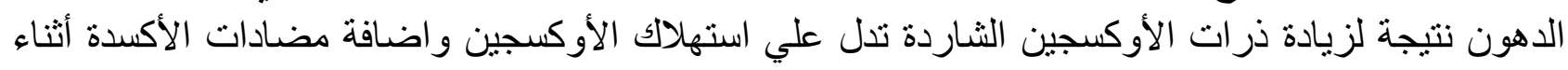

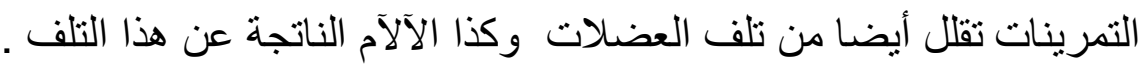

بينما قام كلا من SPENCER-JP,JENNER-A عام 1995 ( 33 ) بدر اسة بعنوان "الأضرار التي تصيب

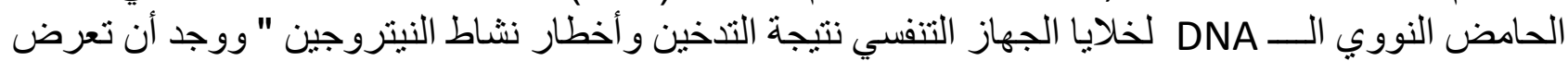

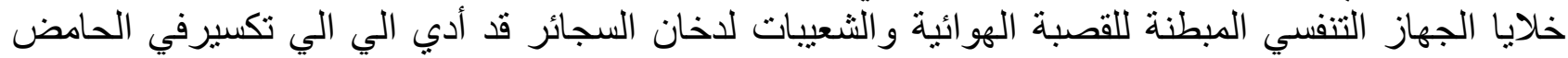

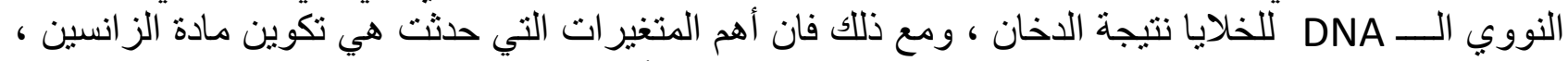

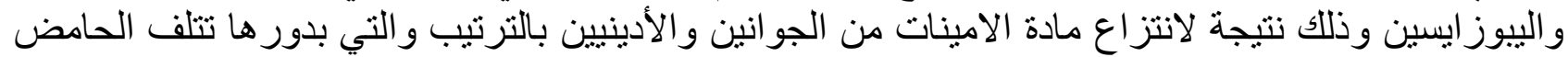
النووي الخلية .

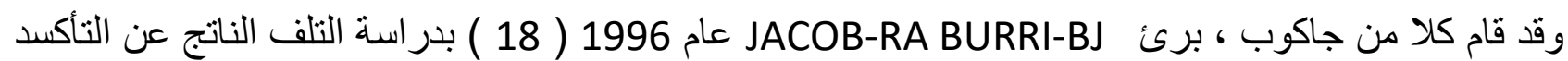
و الوسائل الدفاعية له و أكد كل منهما بأن هذا الموضوع سوف سوف يصبح من اكثر المواضيع شيو عا في المستقبل

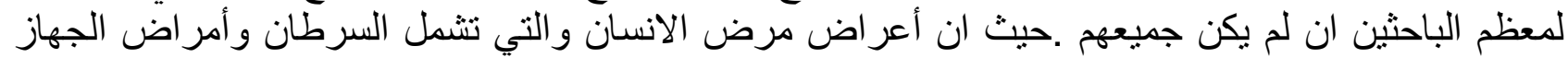

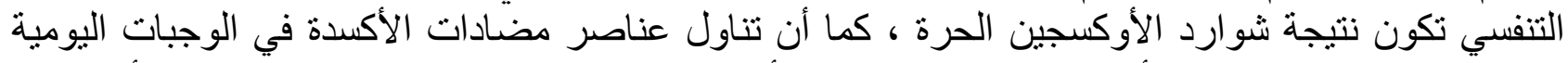

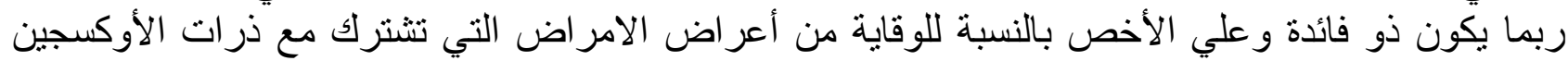

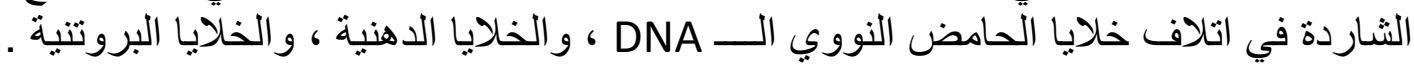

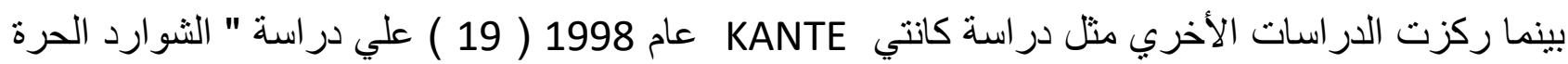

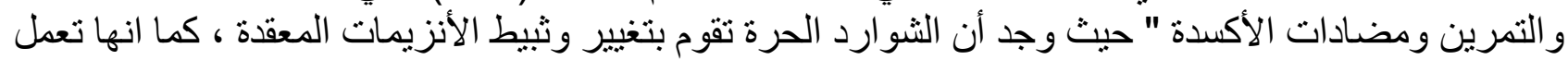
علي تذمير الثريط الور اثي ( DNA , RNA ) مما يؤدي الي حدوث طفر ات وقد ينتج عن هذه الطفرات الات الاصدابة

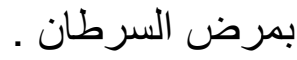

كذلك قام كلا من Baskaran S. Lakshmi S, Prasad PR عام 1999 ( 8 ) بدر اسة بعنوان "تأثنير تدخين

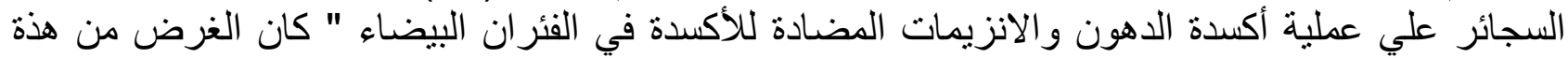

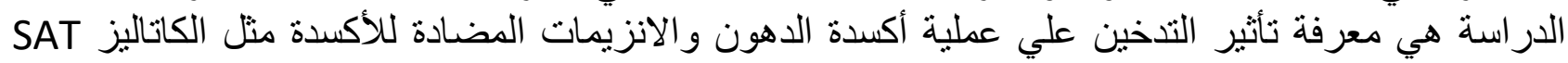

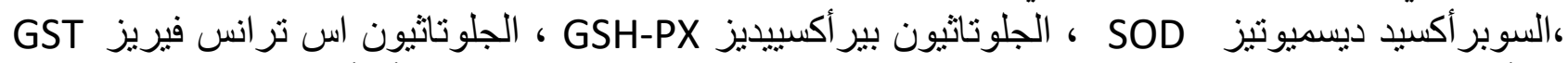

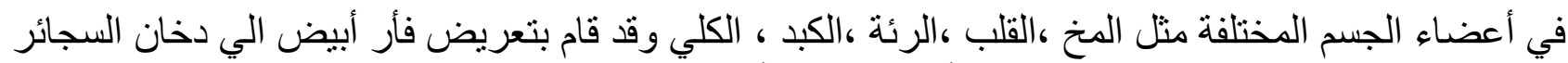

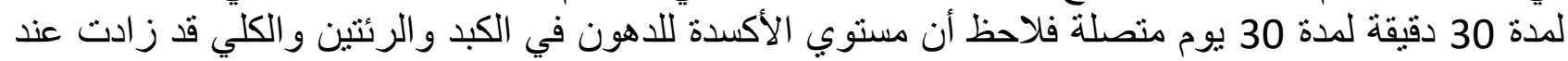

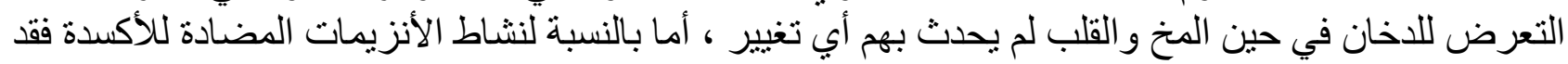

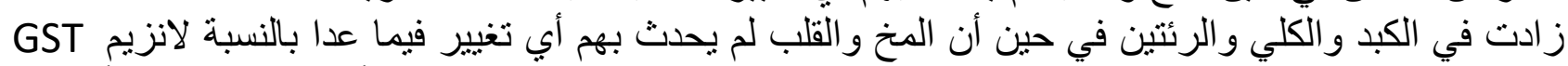

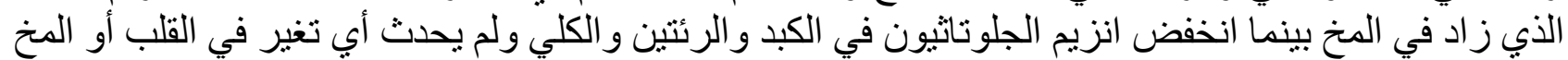

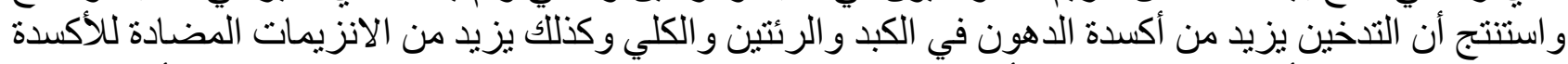

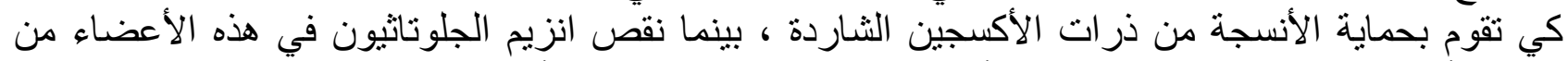

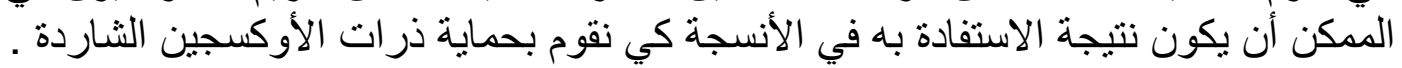


وقد قام كلا من , Dhawan A. Mathur N. Seth PK عام 2001 ( 11 ) بدراسة بعنوان " تأثير التنخين

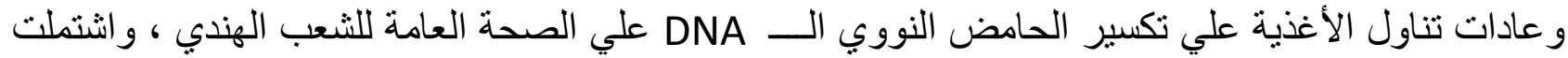

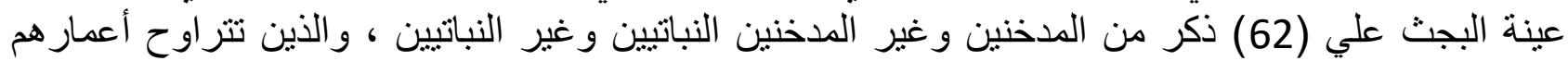

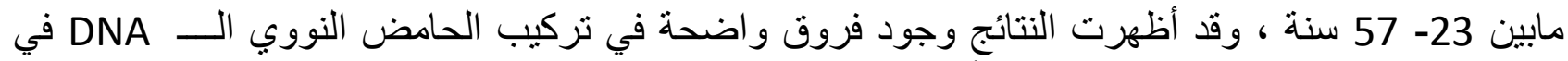

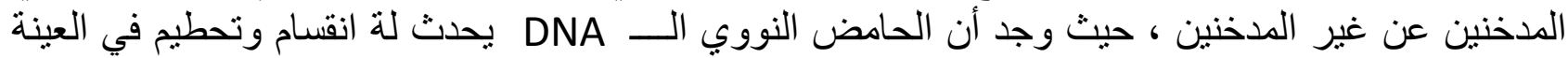

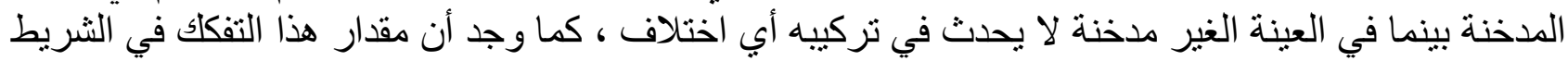

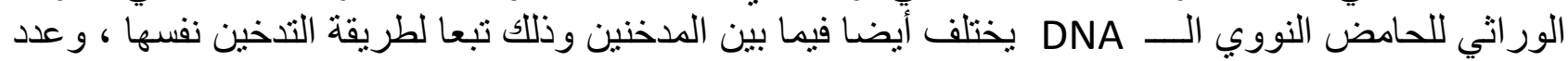

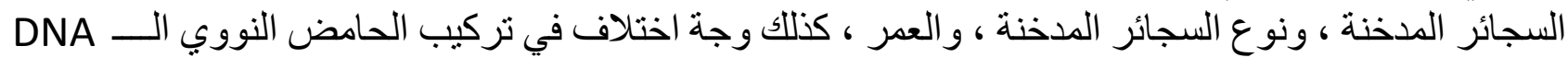
بين الأفراد النباتيين وغير ونوع النباتيين ـ المنين

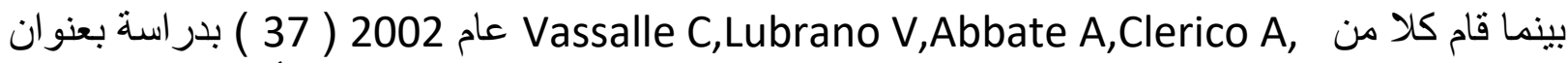

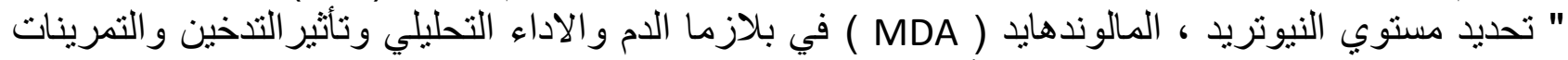

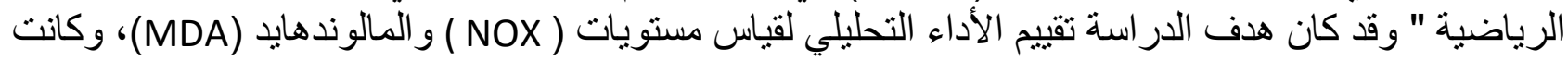

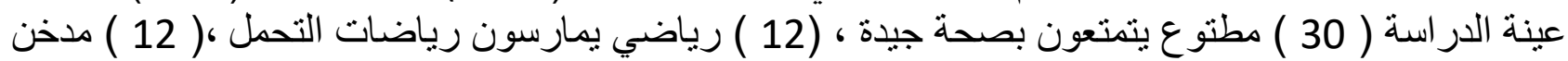

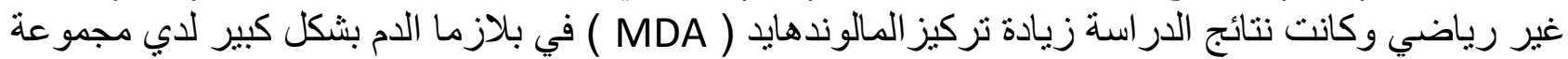

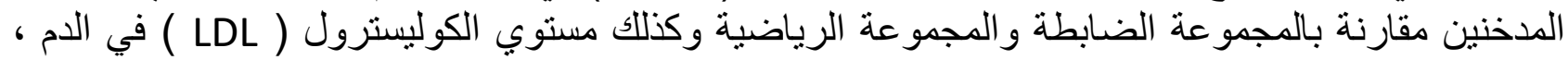

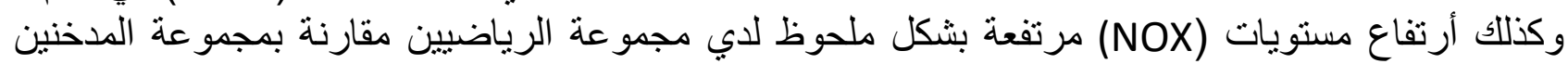
و المجمو عة الضابطة .

كنلك قام Khalid Rahman عام 2007 ( 21 ) بدر اسة بعنوان " الثنو ارد الحرة ومضادات الأكسدة و العو امل

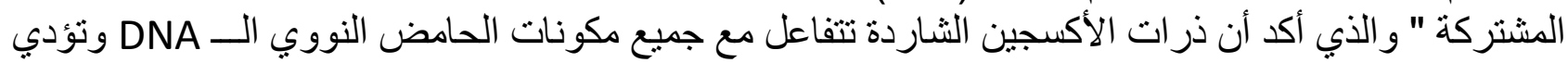

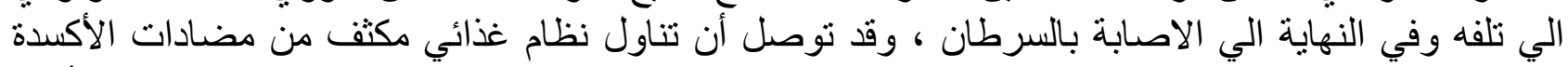

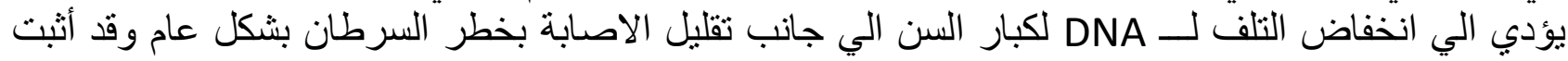

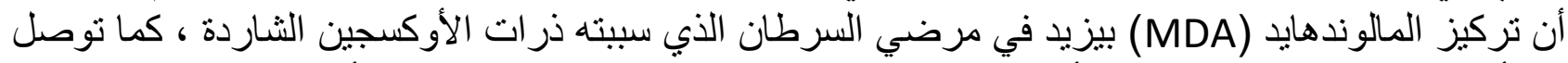

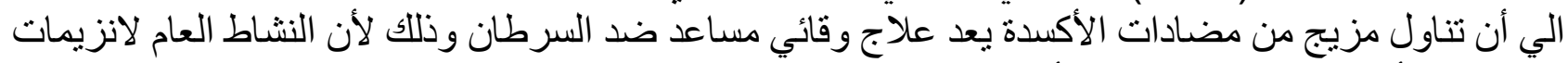

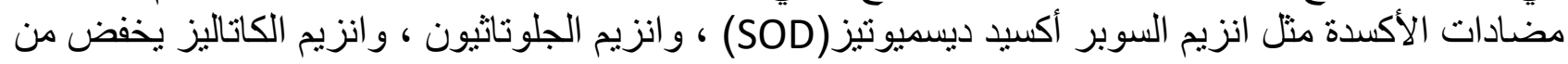

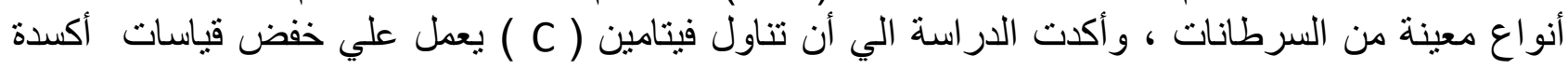

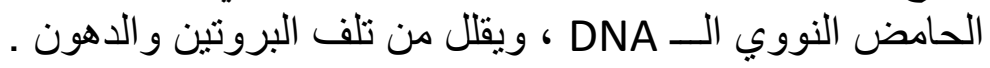

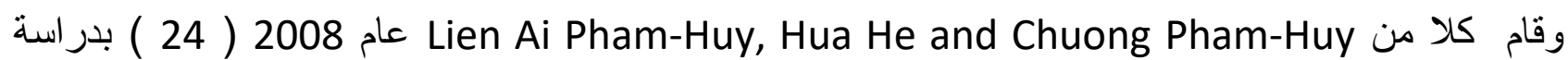

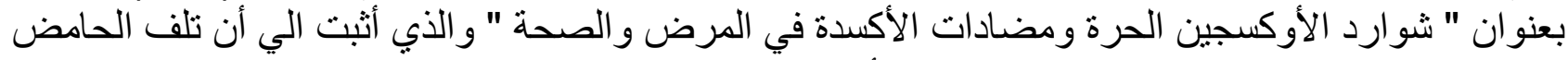

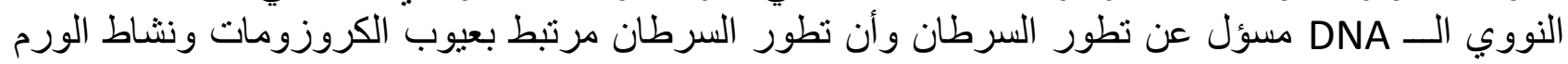

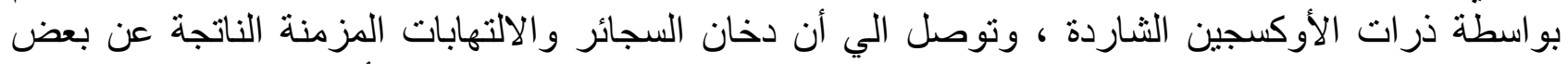

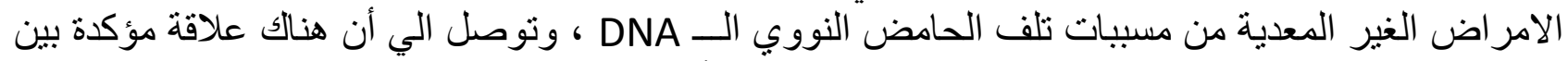

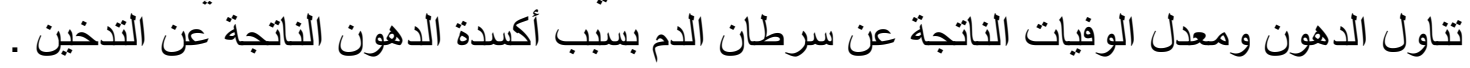

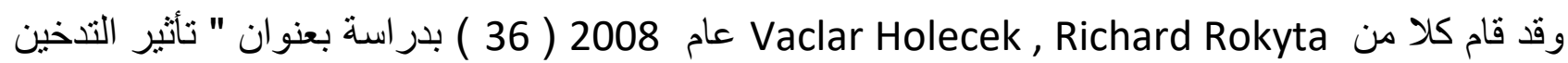
وذرات الأوكسجين الثاردة علي مضادات الاكسدة والتسبب في امر اض معينة " و أكد أن دخان السجائر يؤدي لأني 
الي انتاج عدد كبير من ذرات الأوكسجين الثاردة وكذلك يؤثر علي مضادات الأكسدة وخاصة السوبر أكسيد

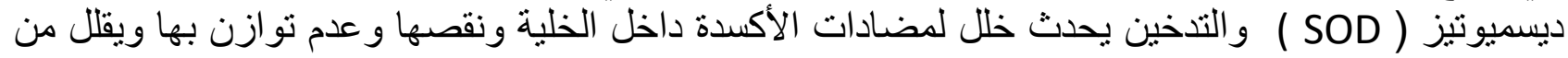

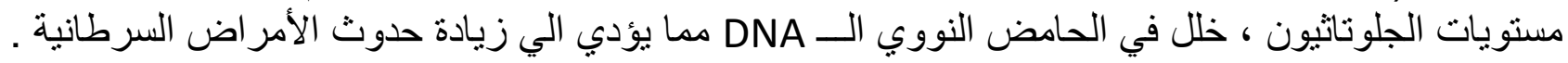

بينما قام كلا من Kristeen Cherney عام 2018 ( 22 ) بدر اسة بعنوان " كيف يؤثر التدخين علي الدورة

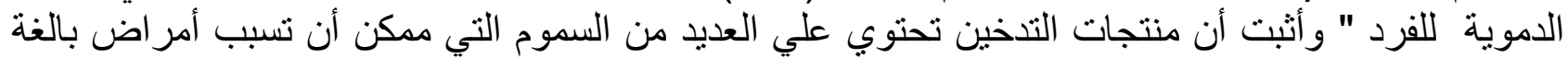

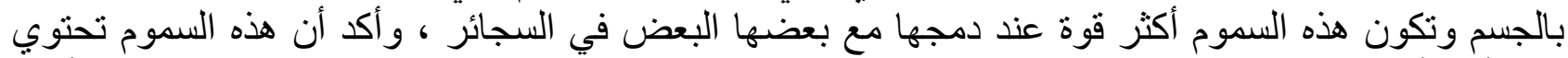

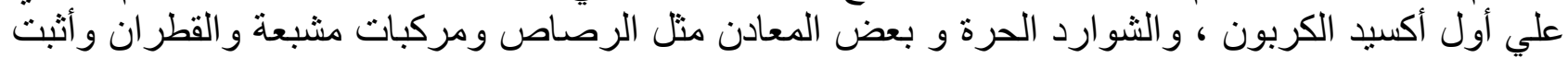

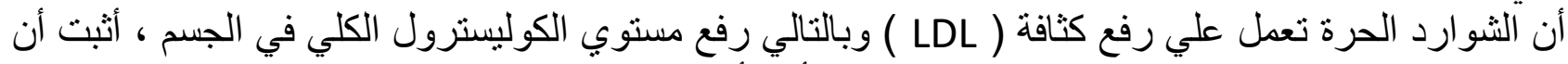

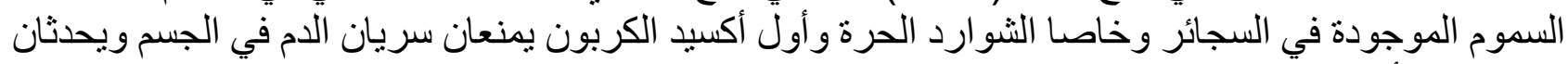
ضيق في الأوعية الآدموية .

بينما قام كلا من Roberto Carnervale, Villoria Cammisotto و آخرون عام 2018 ( 30 و ) بدر اسة

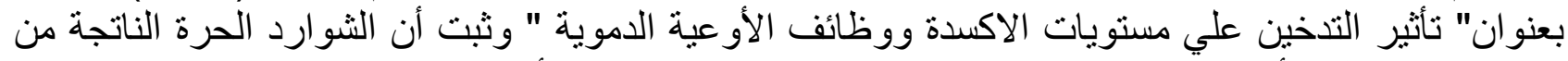

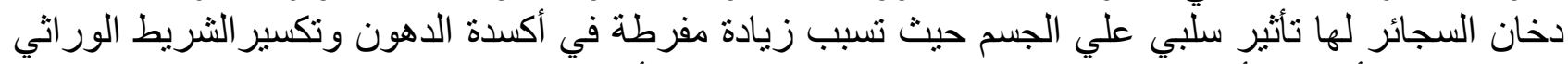

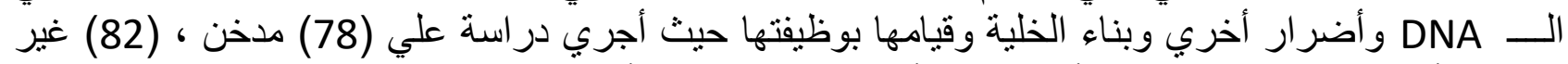
مدخن وأوضحت نتائج الدراسة أن حالة الأكسدة الكلية كانت أعلي في مجموعة المباء المدخنين عن مجموعة غير المدخنين .

استخدام الباحث المنهج الوصفي لملائنته لهذه الدر اسة ،

$$
\text { منهج البحث : البحث : }
$$

$$
\text { مجتمع البحث : مينة : }
$$

أجريت تجربة البحث علي عينة قو امها (20) رياضي من لاعبي الدرجة الأولي في أنشطة كرة السلة وكرة البيد و تتر اوح أعمار هم مابين (20- 30 ) سنة وقد تم تقسيم عينة البحث الي مجمو عتين متكافئتين كالتالي :-

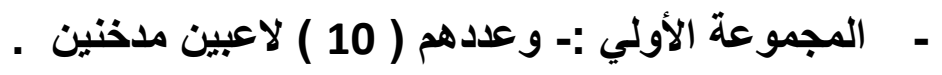

\begin{tabular}{|c|c|c|c|}
\hline الالمعراف & المستوسطي & وحدة القياس & المتغيرات \\
\hline 2.14 & 20.55 & سنة & السن \\
\hline 6.72 & 175.05 & سم & الطول \\
\hline 10.08 & 70.80 & كم & الوزن \\
\hline
\end{tabular}

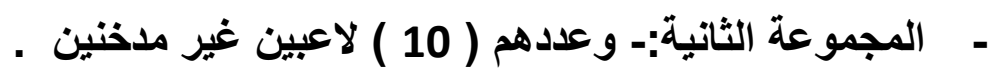

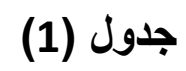

المتوسط الحسابي والانحراف المعياري والالتواء لمجموعة الرياضيين الغير مدحنين ن =10 
جدول (2)

المتوسط الحسابي والانحراف المعياري والالتواء لمجموعة الرياضيين المدحنين ن =10 المبروس

\begin{tabular}{|c|c|c|c|}
\hline المعياري & الحسابي & وحدة القياس & المتغيرات \\
\hline 2.71 & 10.8 & سنة & السن \\
\hline 7.36 & 178.65 & سم & الطول \\
\hline 10.87 & 73.85 & كم & الوزن \\
\hline
\end{tabular}

جدول (3)

المتوسط الحسابي والانحراف المعياري والالتواء لعدد سنوات الممارسة للتدخين ، ومتوسط عدد السجائر

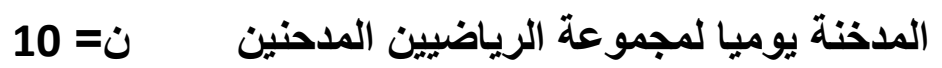

\begin{tabular}{|c|c|c|}
\hline المعياري & الحستوسطي & المتغيرات \\
\hline 5.37 & 17.35 & عدد سنوات الممارسة للتنخين \\
\hline 2.65 & 6.86 & متوسط عدد السجائر المدخنة يوميا \\
\hline
\end{tabular}

أدوات جمع البيانات : حتي يتمكن الباحث من قياس تأثير التندين علي ذرات الأوكسجين الثناردة ، فقد استخدم

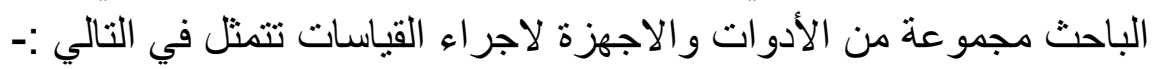
1- 1- قياس الطول بجهاز الرستاميتر .

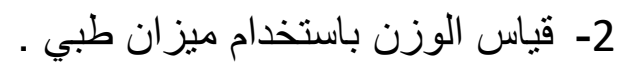
3- جهاز تحليل لاكتات الدم كpectro Photo Meter 4- جهاز الطرد المركزي تلاكئ Centrifuge خطوات اجراء البحث-: ائنة بالنسبة القياسات الخاصة بالثوارد الأوكسجينية الحرة و أكسدة البروتينات وأكسدة الدهون وانزيم السوبر

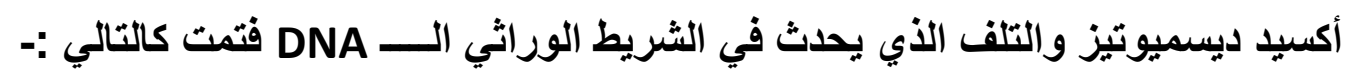


تم أحذ عينة (10 سم) ، تم فصل (2 سم ) من الام لاستخدامها علي سيرم الدم ، تم استخدام بعض الكواثف لحساب التكسير الذي يحدث في DNA ومستوي وأكسدة البروتينات و أكسدة الدهون وانزيم السوبر أكسيد ديسميونيز

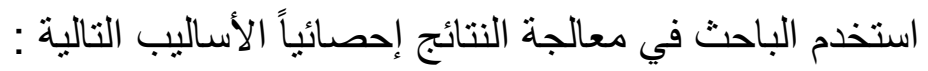

$$
\text { الأسلوب الإحصائي المستخدم : }
$$

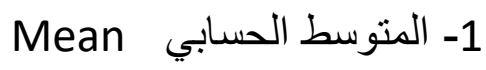
Standard Devitation الانحر افات المعيارية الخوسية 3- اختبار مان وتني وتم ذلك باستخدام الحاسب الآلي . ماني

عرض ومناقشة النتائج :عرض النتائج :- عزصن ومنافئ

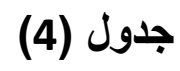

المتوسط الحسابي والاتحراف المعياري ودلالة الفروق بين مجموعثي البحث

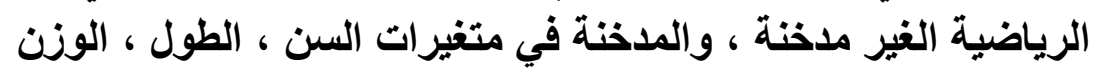

\begin{tabular}{|c|c|c|c|c|c|c|}
\hline \multirow[b]{2}{*}{ قيمة (ت) } & \multirow[b]{2}{*}{ الفرق } & \multicolumn{2}{|c|}{ المدخنين } & \multicolumn{2}{|c|}{ غير المدخنين } & \multirow[b]{2}{*}{ المتغيرات } \\
\hline & & $\varepsilon$ & p & $\varepsilon$ & b & \\
\hline 1.62 & 1.25 & 2.71 & 21.8 & 2.14 & 20.55 & السن ( سنوات ) \\
\hline 1.61 & 3.6 & 3.36 & 178.65 & 6.72 & 175.05 & الطول ( سم ) \\
\hline 0.92 & 3.05 & 10.87 & 73.85 & 10.08 & 70.80 & الوزن ( كجم ) \\
\hline
\end{tabular}

يتضح من جدول (4) عدم وجود فروق دالة إحصائيا بين المجمو عة الرياصية ( الغير مدخنة ، و المدخنة )

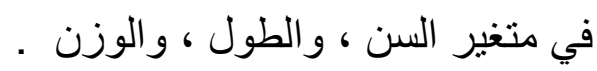


جدول (5)

التوصيف الاحصائي لعينة المجموعة الرياضية الغير مدخنة في جميع المتغيرات

\begin{tabular}{|c|c|c|c|c|}
\hline J & $\varepsilon$ & م & المتفيرات & م \\
\hline 0.37 & 2.14 & 20.55 & السن & 1 \\
\hline 0.15 & 10.08 & 70.8 & 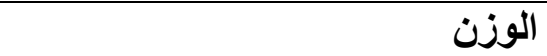 & 2 \\
\hline 0.6 & 6.72 & 175.05 & الطول & 3 \\
\hline 0.43 & 15.71 & 161.75 & SOD انزيم السوبرأكسيد ديسميوتيز & 4 \\
\hline 1.56 & 1.4 & 1.43 & أكسدة البروتينات & 5 \\
\hline 0.59 & 1.44 & 3.33 & أكسدة الدهون MDA & 6 \\
\hline 1.63 & 0.37 & 0.7 & التكسير الذي يحدث في الـ- DNA & 7 \\
\hline
\end{tabular}

يتضح من الجدول أن معدلات الالتو اء لمجموعة الرياضيين الغير مدخنة قد تراوحت بين ( +3 ، ، -3 ) مما يدل علي تجانس العينة في هذة المقاسات .

جدول (6)

التوصيف الاحصائي لعينة المجموعة الرياضية المدخنة في جميع المتغيرات

\begin{tabular}{|c|c|c|c|c|}
\hline J & $\varepsilon$ & 5 & المتغيرات & م \\
\hline 1.9 & 2.71 & 21.8 & السن & 1 \\
\hline 1.06 & 10.87 & 73.85 & 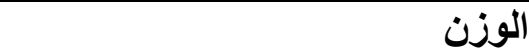 & 2 \\
\hline 1.48 & 7.36 & 178.65 & الطول & 3 \\
\hline 0.29 & 15.57 & 172.5 & SOD انزيم السوبرأكسيد ديسميوتيز & 4 \\
\hline 0.60 & 1.52 & 5.25 & أكسدة البروتينات & 5 \\
\hline 0.57 & 2.25 & 6.43 & أكسدة الدهون MDA & 6 \\
\hline 2.00 & 0.63 & 1.42 & التكسير الذي يحدث في الـ DNA & 7 \\
\hline
\end{tabular}


يتضح من الجدول أن معدلات الالتو اء لهجمو عة الرياضيين المدخنبن قد تراوحت بين ( +3 ، -3 ) مما يدل جدول (7)

يوضح دلالة الفروق بين مجموعتي البحث الرياضيين غير المدخنين ، والمدخنين SOD قياس انزيم السوبر أكسيد ديسميوتيز الرياضيز

\begin{tabular}{|c|c|c|c|c|c|c|}
\hline قيمة (ت) & الفرق & $\varepsilon$ & ? & ن & المتغيرات & p \\
\hline & & 15.71 & 161.75 & 10 & غير المدخنين & 1 \\
\hline 2.12 & 10.75 & 15.57 & 172.5 & 10 & المدخنين & 2 \\
\hline
\end{tabular}

\section{قيمة (ت) الجدولية عند مستوى دلالة (0.05) (2.021)}

يتضح من الجدول وجود فروق دالة إحصائيا بين عينة غير المدخنين والمدخنين عند قياس انزيم

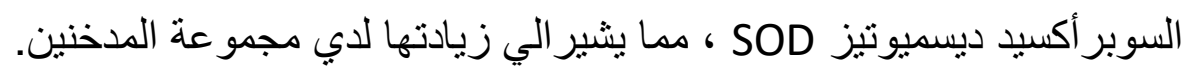

جدول (8)

يوضح دلالة الفروق بين مجموعتي البحث الرياضيين غير المدخنين ، والمدخنين

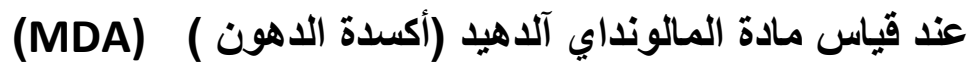

\begin{tabular}{|c|c|c|c|c|c|c|}
\hline قيمة (ت) & الفرق & $\varepsilon$ & ? & $\dot{ن}$ & المتغيرات & s \\
\hline & & 1.44 & 3.33 & 10 & غير المدخنين & 1 \\
\hline 5.17 & 3.1 & 2.25 & 6.43 & 10 & المدخنين & 2 \\
\hline
\end{tabular}




\section{قيمة (ت) الجدولية عند مستوي دلالة (0.05) (2.021)}

يتضح دن الجدول وجود فروق دالة إحصائيا بين عينة غير المدخنين والمدخنين عند قياس مادة المالونداي آلدهيد (أكسدة الدهون ) مDA مما يثير الي زيادتها لدي مجموعة المدخنين.

جدول (9)

يوضح دلاكة الفروق بين مجموعتي البحث الرياضيين غير المدخنين ، والمدخنين عند قياس مستوي أكسدة البروتينات

\begin{tabular}{|c|c|c|c|c|c|c|}
\hline قيمة (ت) & الفرق & $\varepsilon$ & p & $\dot{ن}$ & المتغيرات & r \\
\hline & & 1.4 & 1.43 & 10 & غير المدخنين & 1 \\
\hline 5.56 & 3.82 & 1.52 & 5.25 & 10 & المدخنين & 2 \\
\hline
\end{tabular}

\section{قيمة (ت) الجدولية عند مستوي دلالة (2.021)}

يتضح من الجدول وجود فروق دالة إحصائيا بين عينة غير المدخنين والمدخنين عند قياس مادة المالونداي آلدهيد (أكسدة الدهون ) عند قياس مستوي أكسدة البروتينات مما يشير الي زيادتها لدي مجمو عة المدخنين.

\section{جدول (10)}

يوضت دلاكة الفروق بين مجموعتي البحث الرياضيين غير المدخنين ، والمدخنين

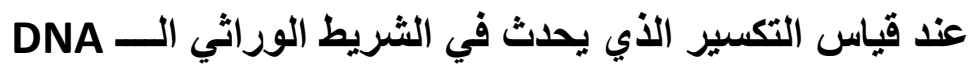

\begin{tabular}{|c|c|c|c|c|c|c|}
\hline قيمة (ت) & الفرق & $\varepsilon$ & r & $\dot{ن}$ & المتغيرات & b \\
\hline & & 0.37 & 0.7 & 10 & غير المدخنين & 1 \\
\hline 4.38 & 0.72 & 0.63 & 1.42 & 10 & المدخنين & 2 \\
\hline
\end{tabular}




\section{قيمة (ت) الجدولية عند مستوي دلالة ( 0.05) (2.021 )}

يتضح من الجدول وجود فروق دالة إحصائيا بين عينة غير المدخنين والمدخنين عند قياس مادة المالونداي آلدهيد (أكسدة الدهون ) عند قياس التكسير الذي يحدث في الثريط الوراثي الــ DNA مدا يشير الي فئي زيادتها لدي مجمو عة المدخنين.

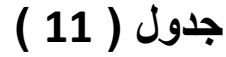

مقارنة بين عينتي البحث غير المدخنين والمدخنبن في جميع المتغبرات المقاسة

\begin{tabular}{|c|c|c|c|c|}
\hline \multicolumn{2}{|c|}{ المدخنين } & \multicolumn{2}{|c|}{ غير المدخنين } & \multirow[b]{2}{*}{ المتغيرات } \\
\hline$\varepsilon$ & b & $\varepsilon$ & b & \\
\hline 15.57 & 172.5 & 15.71 & 161.75 & انزيم السوير أكسيد ديسيموتيز \\
\hline 1.52 & 5.25 & 1.4 & 1.43 & أكسدة البروتينات \\
\hline 2.25 & 6.43 & 1.44 & 3.33 & أكسدة الدهون MDA \\
\hline 0.63 & 1.42 & 0.37 & 0.7 & التكسير الذي يحدث في الثريط الوراثي الــ DNA \\
\hline
\end{tabular}

\section{مناقشة النتائج :}

سوف يستعرض الباحث مناقشة وتفسير نتائج البحث وفقاً البحث وفقاً لترتيب فروض ونتائج البحث كما يلي : أو لا: مناقشة وتفسير نتائج الفرض الأول و الذي ينص علي :

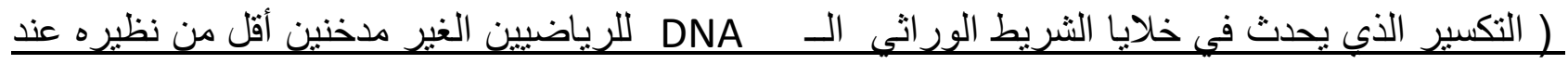
الرياضيين المدخنين (10) : بملاحظة جدول(10) يتضح لنا وجود فروق دالة احصائيا بين عينة البحث الرياضبين غير المدخنين و المدخنين لصالح مجمو عة المدخنين ، حيث وجد أن المتوسط الحسابي لمجموعة الرياضيين الغير مدخنين ( 0.7 ) بينما لمجمو عة المدخنين ( 1.42 ) ولقد بلغت قيمة ( ف ) بين المجموعتين ( 0.72) . 


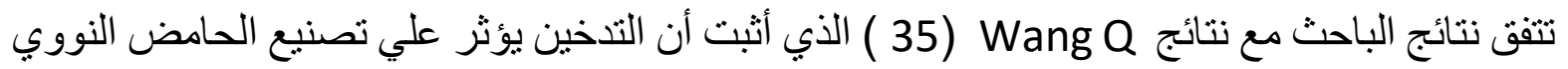

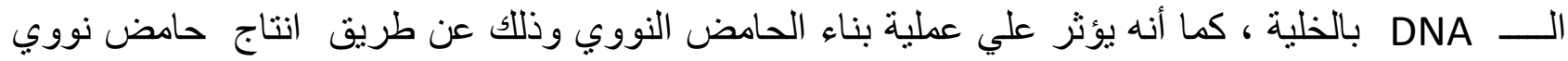
غير طبيعي في الخلية ، كما أن هذا التأثير يزيد بزيادة النعرض لناء لاخدان السجائر وكمية السجائر المدخنة . كما تتفق نتائج الباحث مع نتائج Piperakis SM ( 27 ) الذي استتنج من دراسته أن التدخين هو من أكثر

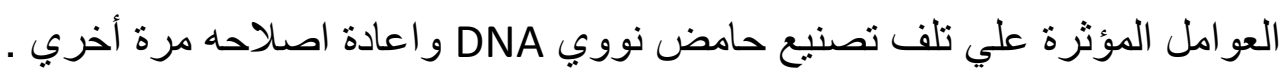

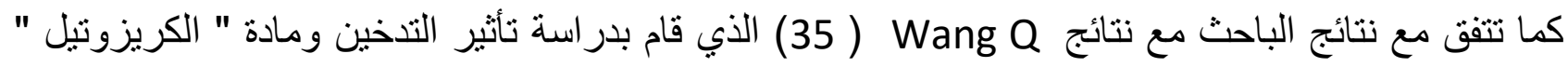

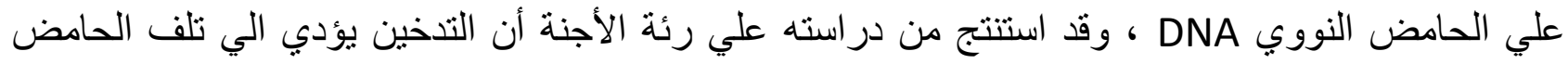
النووي DNA الموجود بالخلية و أيضا الي تنشيط الجينات المسبية للسرطان بالرئة .

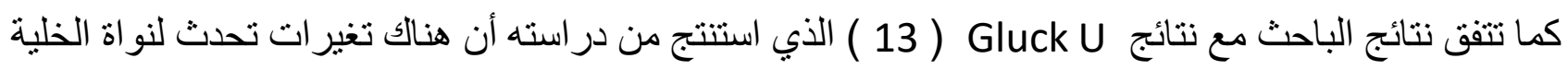

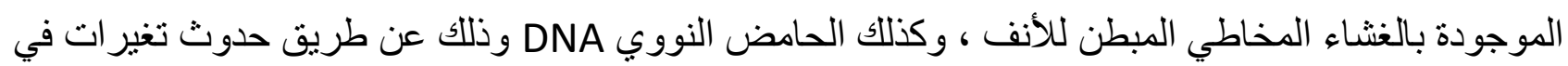

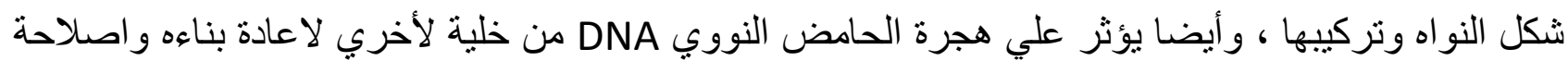

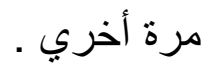

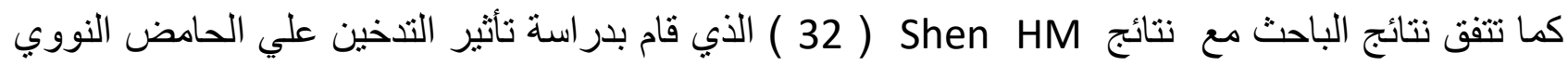

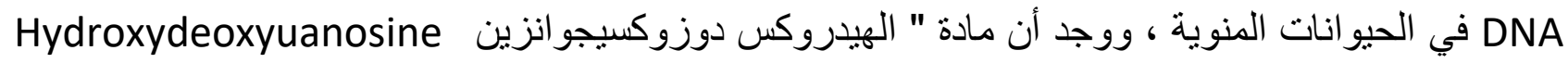

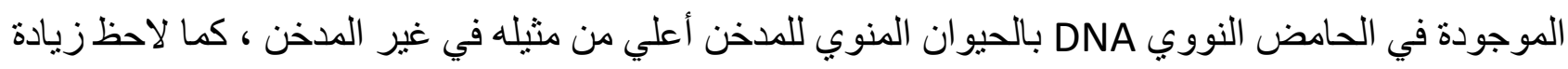

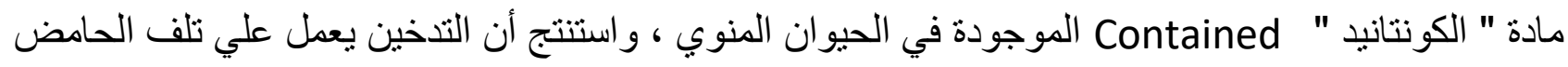

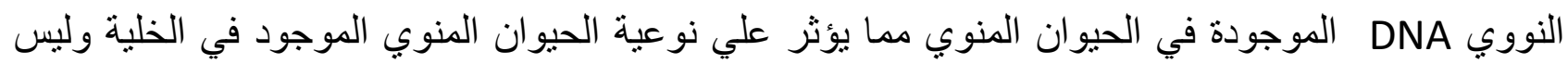
علي عدده أو شكله أو حجمه .

كما تتفق نتائج الباحث مع نتائج Yoshine Y ( 38 ) الذي أنبت أن التنخين يعتبر سببا رئيسيا للاصابة

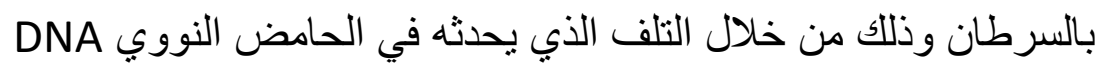
ومما سبق يتضح تحقق صحة الفرض الأول .

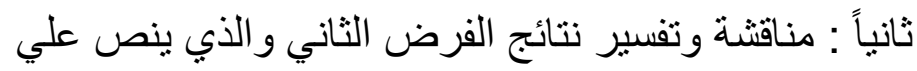
(نسبة أكسدة الدهون و البروتينات لاني للرياضيين الغير مدخنين أقل منها عند الرياضيين المدخنين ).

أولا :- بالنسبة لنسبة أكسدة الدهون

يتضح لنا من الجدول رقم ( 8 ) وجود فروق دالة احصائية بين عينة البحث الرياضيين غير المدخنين والمدخنين وذللك عند قياس مادة المالونداي الدهيد (

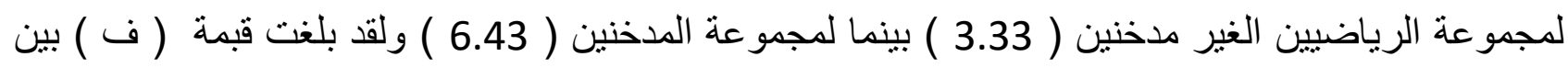

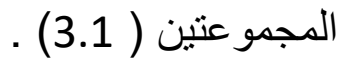




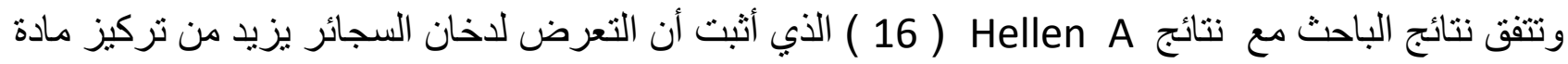

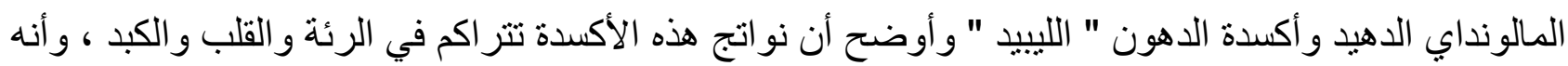
يمكن لقيتامين A أن يقلل من تأكسد الدهون وذلك اذ أخذ بكميات كبيرة لمقاومة نشاط ذر الترات الأوكسجين الثشاردة كما تتفق نتائج الباحث مع نتائج Baskaran S ( 8 ) الذي أكد أن التنخين يزيد من مستوي أكسدة الدهون في

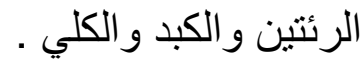

كما تتفق نتائج الباحث مع نتائج , Reddy KV, Kumar PC ( 29 ) التي يؤكد فيها أن زيادة ذرات الأوكسجين الثاردة تؤدي الي زيادة أكسدة الليبيد وتدمير الخلية . تلئه

وكنلك تتفق نتائج الباحث مع نتائج Miller ( 25 ) ) الذي أكد أن دخان السجائر عند استنشاقه في الرئة يعمل

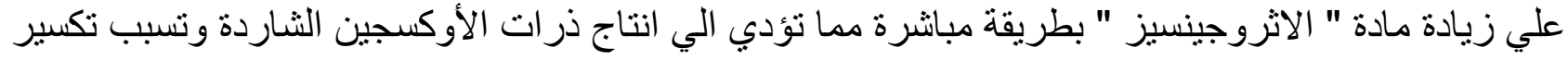

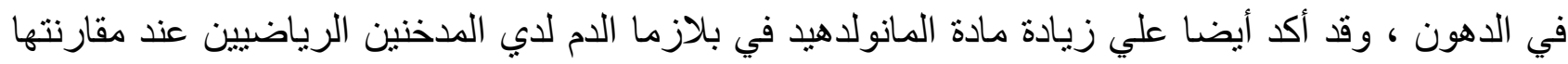

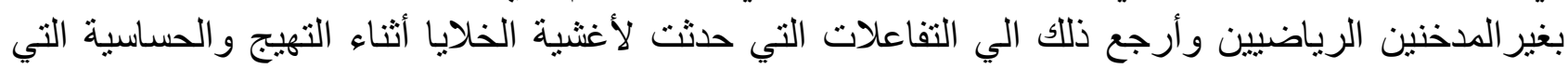

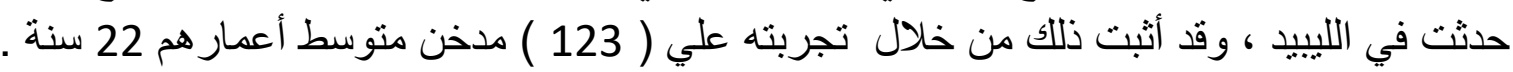
كما تتفق نتائج الباحث مع نتائج Gupta MP ( 14 ) الذي أكد أن استنشاق دخان السجائر يزيد من أكسدة

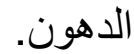

وكذلك تتفت نتائج الباحث مع نتائج Churg A (10 ) الذب أكد أن التنخين يسبب أكسدة سريعة للاهون وذلكان من خلال وجودعلاقة طردية بين زيادة فرص التعائ التعرض للاخخان وبين مادة الدايين المتحدة في الخلايا المبطنة

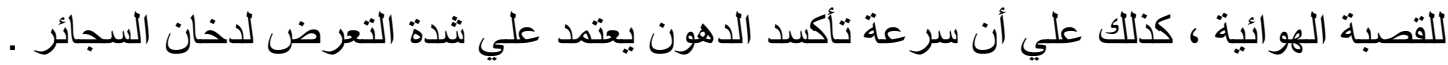

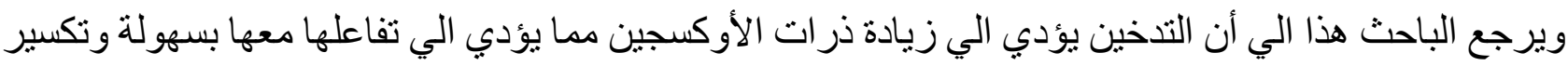

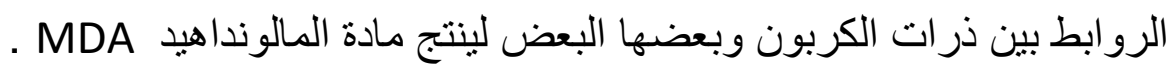

\section{ثانيا :- يالنسبة لأكسدة البروتينات}

يتضح لنا من الجدول رقم ( 9 ) وجود فروق دالة احصائية بين عينة البحث الرياضيين غير المدخنين و المدخنين

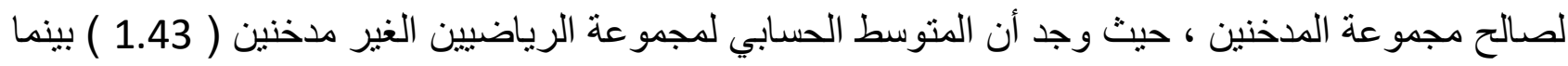

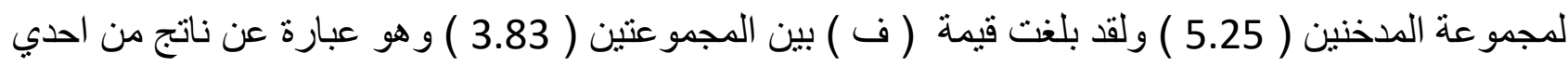

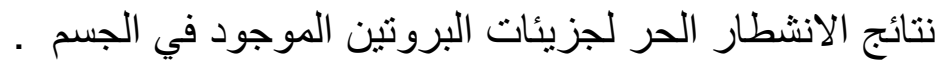

تتفق نتائج الباحث مع نتائج Sharm RN ( 31 ) و الذي قام بدر اسة تأثثر دخان السجائر علي مستوي البروتين

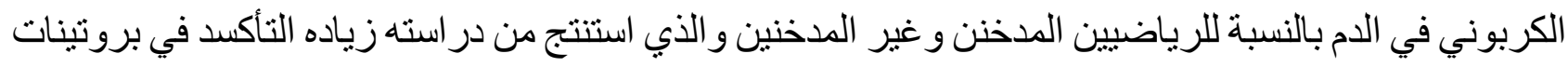

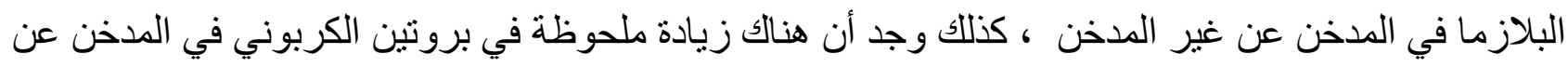

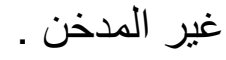


وتتفق نتائج الباحث مع نتائج Lapenna D ( 23 ) و الذي أثنبت أن التنخين يؤدي الي انقسام البروتين الحامل

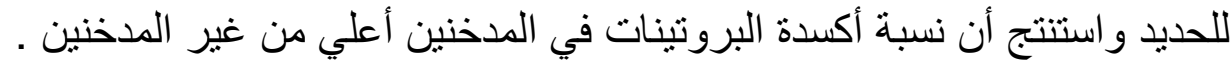
ومما سبق يتضح تحقق صحة الفرض الثاني.

$$
\text { ثالثا : مناقتشة وتفسير نتائج الفرض الثالث و الذي ينص علي }
$$

(نسبة انزيم السوبر أكسيد ديسميوتيز (SOD) كأحد مضادات الأكسدة لدي الرياضيين المدخنين أعلى من نظير هاي عند الرياضيين الغيرمدخنين ).

بملاحظة جدول(7) ينضح لنا وجود فروق دالة احصائيا بين عينة البحث الرياضيين غير الدخخنين والمدخنين

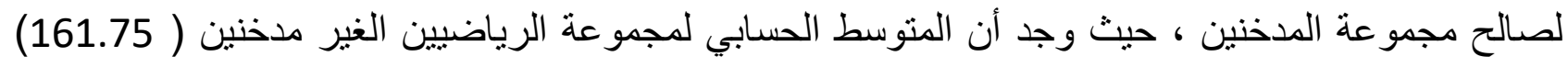

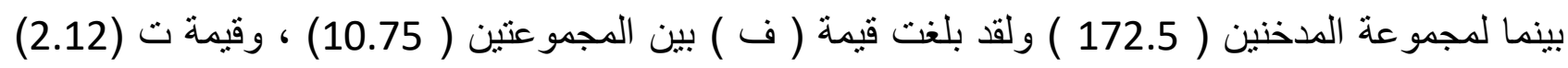
وهو أحد المضادات الطبيعية لأكسدة الثوارد الأوكسجينة.

وتتفق نتائج الباحث مع نتائج Helden A ( 16 ) و والذي أكد أن التعرض لاخان التدخين بزيد من نشاط انزيم السوبر أكسيد ديسميوتيز( SOD ( SOت ).

كما تتفق نتائج الباحث مع نتائج Park EM ( 26 ) و و الذي أثبت أن دخان التدخين بزيد من نشاط انزيم السوبر أكسيد ديسميوتيز ( SOD ) في كل من أنسجة الجسم وخاصة أنسجة الرئة.

كما تتفق نتائج الباحث مع نتائج Halliwell ( 15 ) حيث أثبت أن ذرات الأوكسجين الثشاردة تعمل علي تدمير

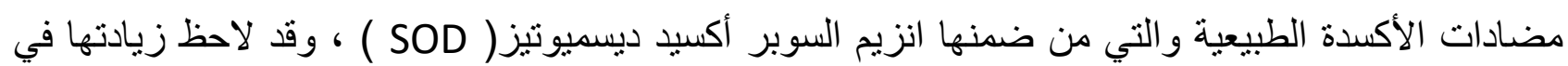

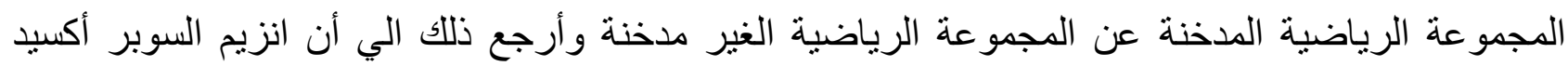

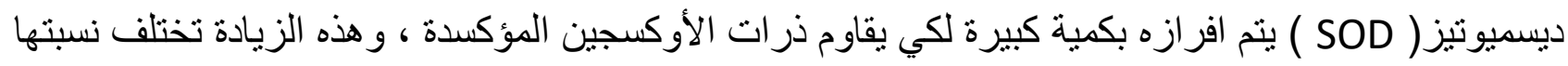
تبعا لكمية السجائر المدخنة لأكسدة الأكسجين .

كما تتفق نتائج الباحث مع نتائج دراسة Baskaran S ( 8 ) ) و الذي أثبت أن دخان التدخين بزيد من مضادات

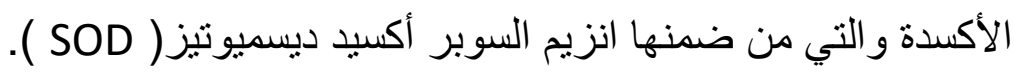

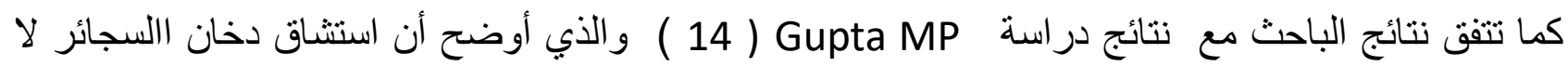

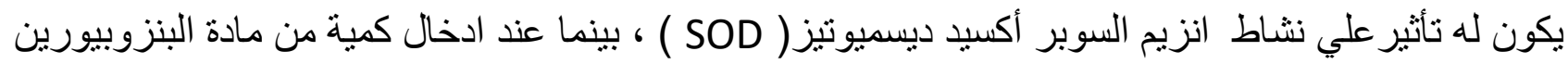

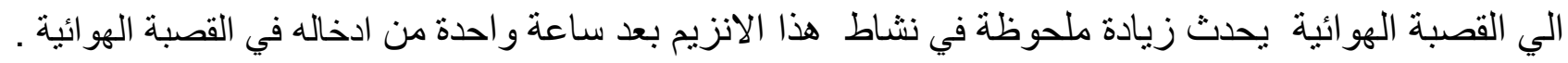

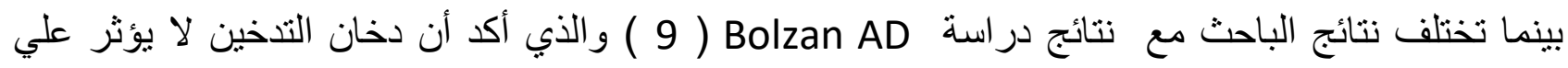

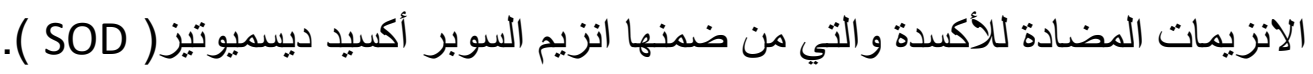


ويرجع الباحث سبب الزيادة في انزيم السوبر أكسيد ديسميونيز( SOD ) للمدخنين عن غير المدخنين الي أن

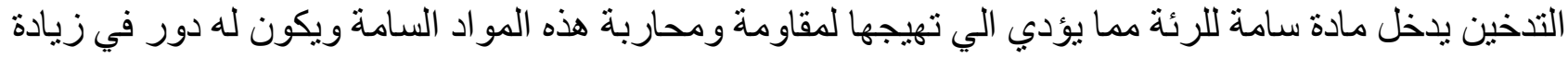

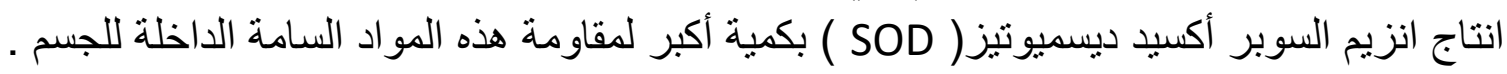

ومما سبق يتضح تحقق صحة الفرض الثالث.

$$
\text { الاستنتاجات :- (1) }
$$

في ضوء نتائج البحث وفي حدود العينة والمنهج المستخدم والعالجة الاحصائية وتحليل النتائج أمكن التوصل الي الاستنتاجات التالية :

1- التدخين يزيد من مقدار الشو ارد الأوكسجينية الحرة في أنسجة الجسم .

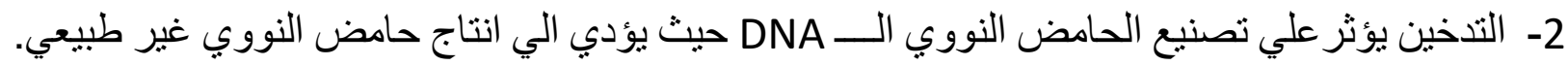

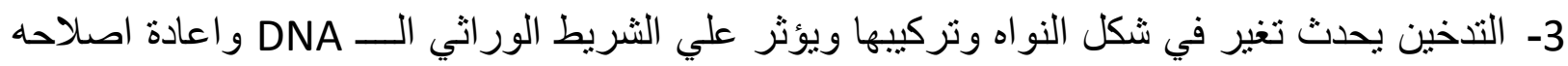
مرة أخري.

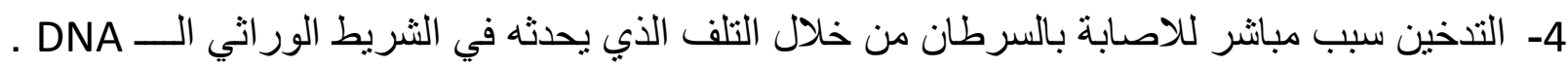

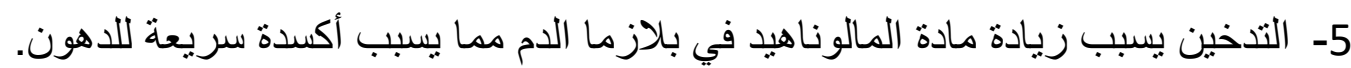

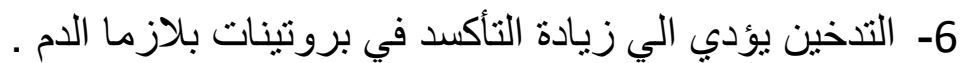
7- انزيم السوبر أكسيد ديسميوتيز (SOD) كأحد من مضادات الأكسدة يتم افرازه بكمبات كبيره ليقاوم ذرات الأوكسجين الثاردة التي بسببها التدخين .

التوصبات :- (1)

في ضوء أهداف البحث وفروضه ونتائجه و النتائج المستخلصة وفي حدود طبيعة البحث وبناء علي ماسبق من

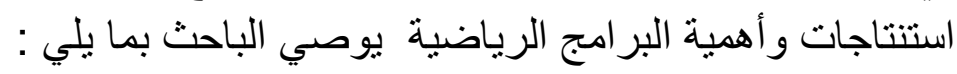
1- علي المدربين بتو عية الاعبين بأضر ار التدخين ، وحثنه علي عدم التدخين .

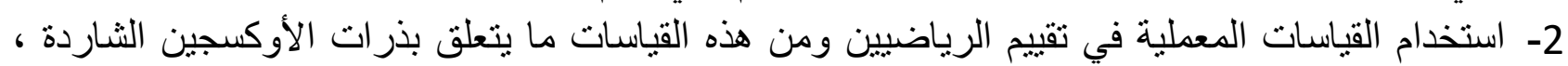
و مضادات الأكسدة . 3- ضرورة اجر اء المزيد من الابحاث العلمية في هذا المجال . 4- عمل در اسة مقارنة بين تأثثر التدخين علي ذراء الات الأوكسجين الثاردة عند الرياضبين وغير الرياضبين المدخنين . 
1- أبو العلا أحمد عبد الفتاح. الاستشفاء في المجال الرياضي. دار الفكر العربي، القاهرة. 1999

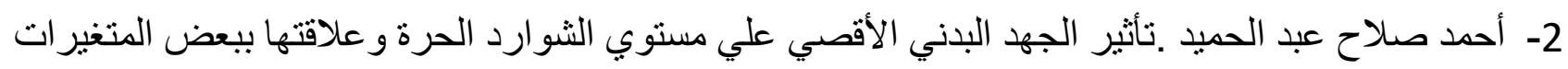

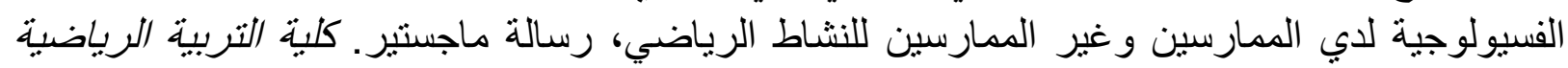
للبنين جامعة حلوان، القاهرة. 1999

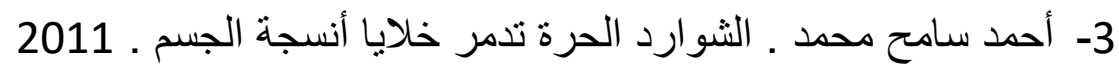

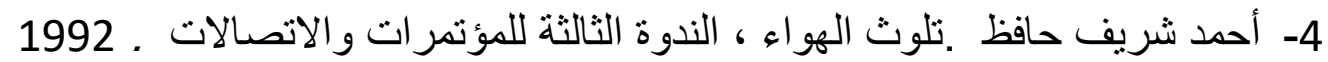

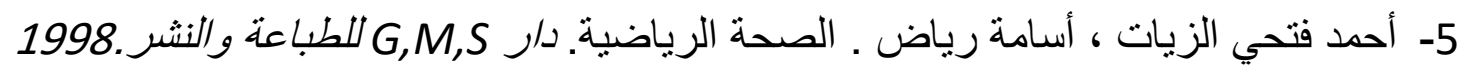

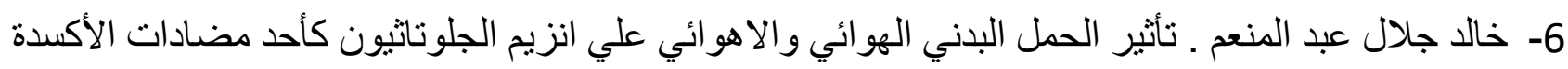

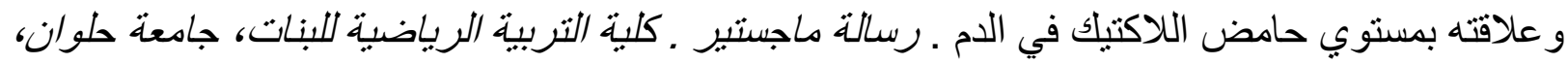

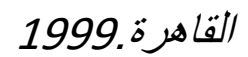

7- سعد كمال طه. الرياضة ومبادئ البيولوجي. 1991 ثانيا: المراجع الأجنبية

8- Baskaran S Lakshmi S, Effect of cigarette smoke on lipid per oxidant enzymes in albino, Department of Biochemistry, Perundurai medical college \& research center. India , 37 (12) : 1196 -200,1999

9- Bolzan AD, Bianchi MS, Bianchi ND. Superoxide dismutase catalase and Glutathione Peroxidase activities in human blood, Influence of sex, age and cigarette smoking. Lnstituto Multidisciplinario De Biologia Celular, La Plata, Argentina, Chin Biochem, 30 (6) : 449-54,1997

10- Churg A, Cherukulli K. Cigarette smoke causes rapid peroxidation of rat tracheal epithelium. Department of Pathology, University of British Columbia, Vancouver, Canada , Jexp Pathol, 74 (2), 127-32. 1993

11-Dhawan A, Mathur N, Seth PK. The effect of smoking and eating habits on DNA damage in Indian Population as measured in the comet assay. Mlutat Res, 474(1-2): 121-8. 2001

12-Fridovich, Superoxide dismutase and adaptation to a paramagnetic gas, J, BIOL. CHEM.1989

13-Gluck U, Gebbers JO, The Cement assay of epithelia measurement of DNA damage for the assessment of genotoxic air pollution, Laryngoscope, 110 (1):123 -5.2000 
14-Gupta MP, KHANDUJA KL, Sharma RR, Effect of cigarette smoker on antioxidant enzymes and lipid peroxidation in the rat. Toxicol Lett, 41 (2): 107- 14. 1988

15-Halliwell, B. and M, Grootweld, The measurement of free human some thoughts for experimentation. FEBS Lett, 213:14. 1987

16-Helen A, Vijaymmal PL, Effect of Vitamin A Supplementation on Cigarette smoke induced lipid Peroxidation, Vet Hum Toxicol , 39 (1) : 18-21.1997

17-Jacason $M, T$, Muscle damage during exercise Possible role of free radicals and protective effect of vitamin E, Proc,Nufer,p.77- 80.1987

18-Jacob-RA, Burri, BJ, Oxidative damage and defense, USA, agricultural Research service, Western human nutrition research center, Sanfrancisco.1996

19-Kanter M, H, Free radical, exercise and antioxidant supper mentation, pro Nutr, 57 (1): 9-13. 1998

20-Kenneth H. Cooper. M, D. Antioxidant revolution, Nelson publisher. 1994 21- Khalid Rahman. Studies on Free Radicals, Antioxidants, and Co-factors, 2

(2):219-36. 2007

22-Kristeen Cherney . What Can Smoking Do To Your Ciculatatory System? , 2018 23- Lapenna D, Gioin S, Mezzetti A, Cifani G, Consoki A, Caccurullo F. Cigarette Smoke

Ferritin And Lipid Peroxidation, Am J Respir Cril Care Med, 151 ( 2PT 1) : 431 -5 .1995

24- Lien Ai Pham-Huy, Hua He, Chuong Pham-Huy. Free Radicals, Antioxidants in Disease and Health, 4 (2): 89 -96. 2008

25- Miller. E, APPLE, L. Jianngl, And T, Risky, Association between cigarette smoking and lipid peroxidation in a controlled feeding study, Circulation, 1097 1101. 1997

26-Park EM, Park YM, Gawk, k. Oxidative damage in tissues of rats exposed to cigarette smoke free radical Biol Med, 1 (5): 79 -86. 1998

27- Piperakis SM, Pertrakou E, Tsilimigaki S, Effect of Pollution and smoking on DNA damage human Lymphocytes, Environ Mol Mutagen , 36 (3): 243-9. 2000 28-Regina Bailey, DNA Definition: Shape, Replication and Mutation. 2018 29-Reddy KV, Kumar TC, Prasad M, Riddanna P, Pulmonary lipid peroxidation and antioxidation defenses during exhaustive physical exercise, The Role of

Vitamin E and selenium, Nutrition, 14 ( 5 ):488- 51 . 1998

30-Roberto Camevale, Vittoria Cammisotto, Francesca Pagano, Cristina Nocella, Effect of Smoking on Oxidative Stress and Vascular Function. 2018 
31- Sharma RN, Deva C, Behra D, Kanduja KL, Reactive oxygen species formation in peripheral blood in different types of smokers, India, J, Med Res, 106 : 475 -480. 1997

32-Shen HM, Chia SE, NIZY, New AL, Lee BL, Ong CN,, Detection of oxidative DNA damage in human sperm and association with cigarette smoking, Reprod Toxicol, 11 (5):675-80 .1997

33-Spencer- TP, Jenner, A, DNA damage in human respiratory tract epit heythlial cell damage by gas phase cigarette smoke apparently species in addition to oxygen radicals, University of London King Collage UK,1995

34- Spiro Max, Spiro TM, Automates Spirometers, Model 110, CDX, Corporatio, USA, 1982

35-Wang Q, Fan J, Wang H, Liu, s, DNA damage and activation of C-ras in human embryo lung cell exposed to chrysotite and cigarette smoking solution, J, Environ Pathol Toxicol, 19 (1-2 ):18 -9. 2000

36-Vaclav Holecek, Richard Rokyta, Research Gate. 2008

37-Vassalle C, Lubrno V, L‘Abbate A, Clerico A, 40 (8): 802 -9. 2002

38-Yoshine $\mathrm{Y}$, Ohshian $\mathrm{H}$, Synergistic induction of DNA Strand breakage by cigarette tar and nitric oxide, Unit of Endogenous Cancer Carcinogenesis, 18 (7): 1359-63.1997 
تأثير التاخين علي ذرات الاوكسجين الشاردة لاي الرياضيين المدخنين والغير المدخنين

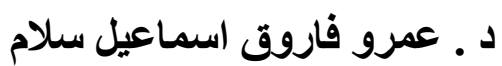

\section{مقدمة ومشكلة البحث :}

هنالك بعض العادات السيئة التي قد تكون مكتسبة من مخالطة الاقران مثل التدخين ، فهو من أهم مشاكل العصر

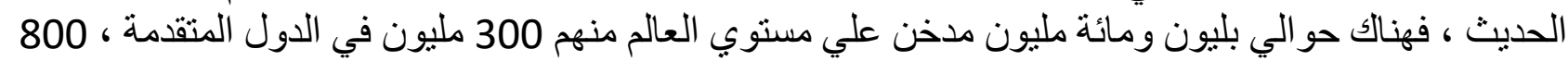
مليون في المجتمعات النامية . فئي

ورغم أهمية الاوكسجين في انتاج الطاقة ورغم فوائدة العديدة للجسم فان للة آثار جانبية مدمرة تبعث علي تكوين

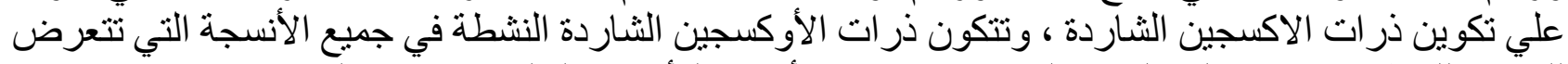

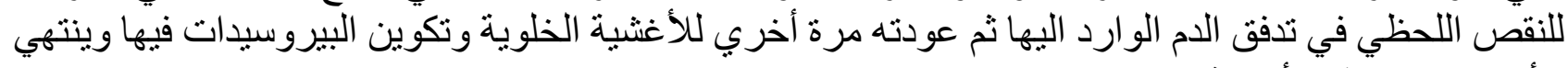

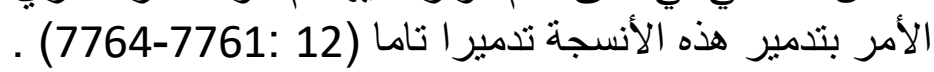

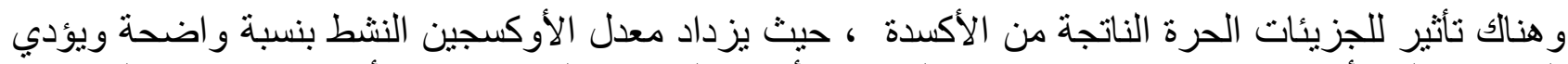

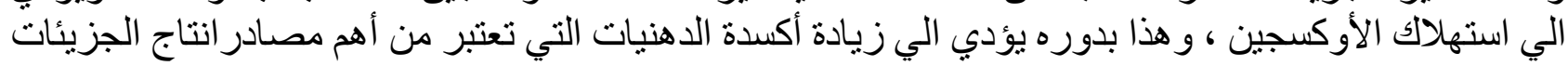

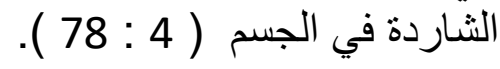

كما أوضح كوبر 1994 Cooper ( 20 ) أنة بالر غم من خطورة الثوارد الحرة الأوكسجينية الا أن

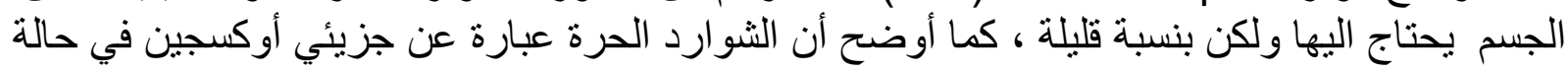
عدم الاستقرارنتيجة انتزاع الكترون منه ونتيجة لهذه الحالة فان هذا الجزئي عندما يقوم بمهاجمة الخلية

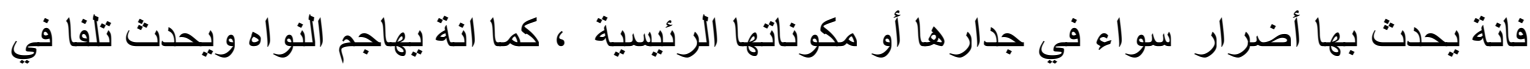

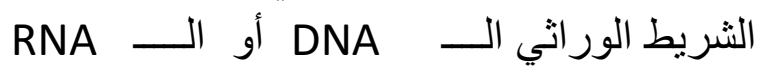

لذا كان من الضروري أن نتعرف علي تأثير التذخين علي ذرات الأوكسجين الثاردة لدي الرياضبين المدخنين و غير المدخنين . لون المنرو 